\title{
What Drives Cross-Country Health Inequality in the EU? Unpacking the Role of Socio-economic Factors
}

\author{
Gintare Mazeikaite $^{1,2}$ (D) $\cdot$ Cathal O'Donoghue ${ }^{2,3} \cdot$ Denisa M. Sologon ${ }^{1}$
}

Accepted: 6 December 2020 / Published online: 4 January 2021

(c) The Author(s) 2021

\begin{abstract}
Despite comparable living standards and a nearly universal healthcare provision, there are large cross-country differences in population health in the European Union. More than half of this variation remains unexplained after accounting for macro-level factors. This paper investigates how individual-level differences in demographic characteristics, education, labour market factors and income shape the prevalence of poor self-assessed health in the EU. A semi-parametric decomposition approach is used, which relies on constructing synthetic distributions of health that would prevail in each country if they had similar distributions of socio-economic factors as the country with the best self-assessed population health-Ireland. We find clustering of decomposition results within EU regions. When compared with Ireland, differences in the examined factors explain up to a third of excess poor health in the Southern and Central and Eastern European countries. On the other hand, we could not explain health differences between Ireland and the other Western European countries, which tend to have poorer self-assessed population health but more favourable distributions of socio-economic factors. Cultural differences in reporting styles may be responsible for this result.
\end{abstract}

Keywords Health inequality $\cdot$ Decomposition $\cdot$ Socio-economic factors $\cdot$ EU-SILC $\cdot$ Crosscountry

JEL Classification: $\mathrm{I} 14 \cdot \mathrm{J} 00 \cdot \mathrm{N} 34$

Gintare Mazeikaite

gintare.mazeikaite@liser.lu

1 Luxembourg Institute of Socio-Economic Research (LISER), 11 Porte des Sciences, 4366 Esch-sur-Alzette, Luxembourg

2 Maastricht University, Minderbroedersberg 4-6 6211 LK, Maastricht, The Netherlands

3 National University of Ireland, Galway, University Rd, Galway, Ireland 


\section{Introduction}

National income is a good predictor of population health at low levels of economic development but it fails to account for much of the cross-national variation among rich nations (Preston 1975; World Bank 1993). The Preston curve from 1975 can be used to tell the story of health in the EU, which comprises countries with high living standards, yet significantly different health profiles. For example, in 2010, an average person born in Lithuania was expected to live around 9 years less than an average Italian. ${ }^{1}$ This does not mean that all Lithuanians are destined to live shorter lives: it rather signals that some of them will not achieve as high levels of health as their Italian counterparts. In other words, a part of the explanation for the observed variation in life expectancy lies in health inequalities within each country.

A number of studies have turned to examining within-country health inequalities in order to understand population health. One of the first notable studies was the Black Report (Black 1982), which exposed staggering differences in health across socio-demographic groups in Britain. ${ }^{2}$ Since then, it has been shown that systematic and persistent health inequalities exist worldwide, whereby individuals with lower income, education, and occupational status tend to enjoy considerably worse health (Kunst et al. 2005; Mackenbach et al. 2008; Adler and Ostrove 2006). Poor health attributed to low socio-economic status can be considered not only unethical but also costly: due to the loss of productivity, it may account for as much as $1.4 \%$ of GDP in the EU (Mackenbach et al. 2011).

High educational attainment, income, and occupational status do not guarantee favourable conditions for health, but they are good predictors of life circumstances that affect health. First, one's socio-economic position often signifies command over resources that are important for good health, which can be material, behavioural, psychosocial and healthcare related (Solar and Irwin 2010). Second, high position is associated with a reduced exposure and vulnerability to adverse life circumstances and economic shocks (Solar and Irwin 2010; WHO 2013). The extent to which (un)favourable life circumstances cluster together and accumulate over time among different population groups determines the size of socio-economic health inequalities, and consequently shapes population health in each country (Bartley et al. 1997; Korpi 2001; Whitehead 1992).

Cross-national differences in mortality and morbidity are well-documented, yet the factors responsible for this variation remain largely unexplained (Costa-Font and HernándezQuevedo 2013). Underlying reasons are often sought in within-country health inequalities. Studies have shown systematic income, education and occupation-related health inequalities in both physical and self-assessed health in the EU, yet the findings on the magnitude of these inequalities vary depending on the data and methodology used (van Doorslaer et al. 1997; Eikemo et al. 2008c; Marmot and Shipley 1996). A number of studies have reported varying patterns of health inequalities and population health across different regions and welfare state regimes (Eikemo et al. 2008b, c; Popham et al. 2013; Espelt et al. 2008; Kunst et al. 2005; Cavelaars et al. 1998). While the complete cross-country rankings remain sensitive to research design, it is commonly agreed that institutional and socioeconomic factors play an important role in shaping population health. However, a more

\footnotetext{
1 Life expectancy by age and sex. Statistics Database (EUROSTAT 2010a)

2 The Black Report, commissioned by the Department of Health an Social Security in the UK, is considered to be one of the landmark studies on social health inequalities.
} 
holistic approach is needed to understand how differences in the distribution of socio-economic factors shape cross-country health inequality.

Since the Black Report, there has been a growing interest among national governments, scholars and international organizations in monitoring and tackling health inequalities and improving population health. These priorities are the core of the European health policy framework Health 2020, which aims to "significantly improve the health and well-being of populations" and "reduce health inequalities" (WHO 2012). This paper aims to provide more evidence on the social causes of cross-country health inequality. In particular, it aims to explain how inequality in population health across the EU is shaped by cross-national differences in the distribution of demographics, education, labour market characteristics and income. Our underlying hypothesis is that a part of the explanation why some countries fail to achieve good health lies in unfavourable distributions of socio-economic factors. To test the hypothesis, we decompose the differences in the prevalence of poor selfassessed health between each analysed country and Ireland-the country which has the lowest prevalence of poor subjective health in the EU in our study and elsewhere (Olsen and Dahl 2007; Hildebrand and Van Kerm 2009) and thus serves as a benchmark for crosscountry comparison. ${ }^{3}$ We use data from the EU Statistics on Income and Living Conditions (EU-SILC) and classify countries into three regions-Western Europe, Southern Europe and Central and Eastern Europe - in order to examine whether we find regional differences in the results.

We employ a micro-econometric decomposition approach in the spirit of Oaxaca (1973) and Blinder (1973), which relies on comparing the actual distributions of health with a series of counterfactual distributions that would prevail if one or several factors at a time were imported from one country to another. This approach has been initially used to explain wage differentials between different demographic groups. It has been extended to accommodate the differences in income and other outcomes between groups and over time beyond the mean, and more recently to incorporate the complexity of tax-benefit systems as explanatory factors (Bourguignon et al. 2007; Bargain 2012; Sologon et al. 2017). In the health economics literature, Oaxaca-Blinder type decompositions have been used to explain income-related inequalities in self-assessed health across countries and in a country over time (Siegel et al. 2014; van Doorslaer and Koolman 2004), socio-economic waiting time gaps (Johar et al. 2013) and geographical and socio-demographic gaps in morbidity and mortality (Van de Poel et al. 2009; Johnston and Lee 2011). However, we are not aware of studies which have used this decomposition approach to examine cross-country variation in self-assessed health, which could greatly enhance our understanding of how socio-economic factors contribute to the observed inequality in health in the EU.

The approach used in this paper relies on the semi-parametric decomposition technique proposed by DiNardo et al. (1996) to estimate how the whole distribution of poor selfassessed health varies with the underlying factors across countries. First, we obtain the effects of each factor in the sequential decomposition. Second, since the proposed approach suffers from the problem of path dependence (the effects of each factor may vary depending on the order in which they are introduced), we analyse how the results compare under two additional scenarios. By doing this, we aim to illustrate the debate discussed in Fortin et al. (2010) in regard to the path dependence in the detailed decomposition. The degree of sensitivity of the results to the decomposition sequence is likely to give an idea of the size

\footnotetext{
3 The choice of Ireland as a benchmark country is also in line with the concept of the "highest attainable standard of health", which is the cornerstone of the WHO constitution.
} 
of interactions between different factors, which are often ignored when choosing a particular order of decomposition or averaging the effects over all possible sequences. While the findings of the study do not necessarily imply causality, uncovering the quantitative strength of these relationships across countries has the potential to inform policy makers on the key areas to focus on in order to reduce socio-economic health inequalities and improve population health.

We find that the examined factors taken together explain up to a third of excess poor health in most of the analysed countries, except the Western European countries. Since other Western European countries tend to do better than Ireland with respect to more objective health indicators, differences in the reporting of self-assessed health are among the likely factors that could help explain the latter result. We also find variation of the decomposition results by regions in Europe. As expected, the effects of most of the factors remain significant with different decomposition sequences but the magnitude varies, which confirms that interactions are important and merit further investigation.

\section{Theoretical Framework}

Different frameworks exist to date which attempt to conceptualise the determinants of health and health inequalities (Graham 2004; Solar and Irwin 2010; Whitehead et al. 2001a). Many studies distinguish between upstream and downstream factors that shape population health (Galea et al. 2010; Whitehead et al. 2001b; Mackenbach and Bakker 2003). Downstream factors are individual factors that directly affect health, such as nutrition, physical activity, working and living conditions. Upstream factors, on the other hand, are factors that occur as a consequence of social stratification processes that divide individuals into different positions by social status, wealth and income. These, in turn, shape access to material, psychosocial, behavioural resources and healthcare (Solar and Irwin 2010). The literature that examines downstream factors emphasizes the role of individual agency, while the latter acknowledges the role of institutions, culture and societal values in shaping patterns of health and disease (CSDH 2008). In the following paragraphs, we discuss the pathways through which upstream factors, such as income and education, shape health inequalities and population health.

Education is commonly obtained early in life, and therefore it reflects early life circumstances (Lynch and Kaplan 2000; Galobardes et al. 2006). Better educated people are more likely to be employed, have full-time and more fulfilling jobs, and higher paid jobs. In addition to this, they tend to be more receptive to health messages, have healthier lifestyles and be better able to find suitable health services (Galobardes et al. 2006; Adler and Newman 2002; Cutler and Lleras-Muney 2006). Finally, education is linked to a greater sense of control of one's life and higher levels of social support, which has been shown to affect health through increased immune response and lower risk of stress-related diseases (Ross and Mirowsky 1995). Education is typically measured by years of full-time education or the highest level achieved (Eikemo et al. 2008b; Shavers 2007) and its effects on health tend to increase with the years of education (Cutler and Lleras-Muney 2006). Because it is achieved early in life, education is considered to be less subject to reverse causality than income and occupation (Mackenbach et al. 2015; Duncan et al. 2002), yet its importance for good health might be overlooked when other socio-economic indicators are accounted for (Lahelma et al. 2004). 
Occupational grade and labour market status are among the factors most often studied in relation to health and mortality (McKee-Ryan et al. 2005; Kunst et al. 1999). Occupational grade has been found to be associated with self-rated health, mental and physical health, such as the presence of long-standing illness and a number of diseases (Lahelma et al. 2005). Lower occupation might affect health through poor working conditions, such as the higher exposure to occupational hazards and toxic compounds, health-damaging behaviours and psychosocial stress (Shavers 2007; Kunst et al. 1999; Baum et al. 1999). Work-based stress combined with a lack of autonomy over one's work are believed to be the psychosocial factors that can cause physiological changes, such as increased risk of cardiovascular diseases and reduced immune system response (Solar and Irwin 2010). It has been shown that the gaps in mortality between different occupational grades persist in old age and tend to widen with age (Marmot and Shipley 1996).

Labour market status is shaped by job opportunities, institutions, policies and cultural values (Giavazzi et al. 2009). Entering unemployment is associated with a decline in income, social position and self-esteem, and prolonged periods of unemployment are believed to be the cause of chronic stress and in turn issues with mental and physical health (Bartley 1994; Bartley and Plewis 2002; Korpi 2001). On the other hand, having secure employment with satisfying working conditions is related to the slower development of limiting illness and shorter duration of illness (Bartley et al. 2004). Varied effects of unemployment on physical and mental health have been found across different socio-economic groups as well as across countries with different levels of income inequality and unemployment protection (Paul and Moser 2009).

Income is an economic asset that ensures access to material conditions important for health, such as proper nutrition, housing and in some cases access to healthcare (Adler and Newman 2002). In addition, it affects health indirectly, such as through the ability to participate in society and feel in control of one's life circumstances, which helps prevent stress and immune system failures (Marmot 2002). Material deprivation and financial strain, on the other hand, are associated with a decline in mental and physical health (Price et al. 2002). On the individual level, a strong association between income and health has been found for a number of industrialised countries: US (Ettner 1996; Braveman et al. 2010), Germany (Frijters et al. 2005), UK (Benzeval and Judge 2001; Benzeval et al. 2000; Ecob and Davey Smith 1999) and elsewhere in the EU (Mackenbach et al. 2005). The shape of the relationship between income and health tends to be curvilinear, with diminishing and sometimes reversing association between income and health at high levels of income (Ecob and Davey Smith 1999; Mackenbach et al. 2005). The strength of the income-health gradient has been found to vary across different welfare states (Jürges 2009; Eikemo et al. 2008c; van Doorslaer et al. 1997).

Population health is also shaped by the demographic structure. Most of the demographic factors can be classified as downstream factors because they directly affect health (age, for example) and others may be socially constructed (ethnicity) and therefore share some characteristics of the upstream factors. For example, married individuals tend to enjoy better health, which could be explained either by selection effects (healthier individuals are more likely to get married) or an increased propensity to take action during illness while married (Verbrugge 1979; Waldron 1996). In addition to this, substantial health differentials have been found across ethnic and racial groups (Smith et al. 1998; Charasse-Pouélé and Fournier 2006), which have been attributed to social exclusion, biology and lifestyles, among other factors (Smith et al. 2003). Finally, a somewhat controversial role is played by gender: females tend to report poorer health and more daily limitations but at the same time have a higher life expectancy than males (Nusselder et al. 2010). 
Recent studies have examined how population health varies across different welfare state regimes (Bergqvist et al. 2013), concluding that more generous welfare provision is related to better population health (Brennenstuhl et al. 2012; Ferrarini et al. 2014). The regime approach originally follows Esping-Andersen (1990), who proposed a grouping of countries with respect to the degree of decommodification, social stratification and social welfare provision. However, welfare state typologies developed since 1990 largely overlap with regional classifications (Eikemo et al. 2008a) and in some cases lack a theoretical explanation. For example, it has been argued that there is no Central and Eastern European welfare cluster as these countries have followed very distinct paths since the fall of communism (Hacker 2009). In addition, countries undertook various consolidation measures in the face of the 2008 economic crisis, which might have affected the make-up of the traditional social welfare states. In order to avoid this controversial debate, we group countries by European regions, keeping in mind the regional differences in the economic, social and institutional aspects across the EU.

In this paper, we examine how individual-level factors such as education, labour market status, income and demographics shape differences in self-assessed health in Europe. We also examine whether results vary by European regions, which may shed some light on the macro-level factors that give rise to differences in self-assessed health in the EU.

\section{Decomposition Approach}

Various micro-econometric decomposition approaches in the spirit of Oaxaca (1973) and Blinder (1973) can be used to decompose the difference in the prevalence of poor health into the underlying factors between any two countries. In an aggregate decomposition, the difference between two distributions of health (Eq. 1) can be decomposed into the part explained by all factors of interest taken together (Eq. 2) and the other factors (Eq. 3) in the following manner:

$$
\begin{gathered}
H_{B}-H_{A}= \\
H_{B}-H_{B}^{c f} \\
+H_{B}^{c f}-H_{A}
\end{gathered}
$$

where $H_{A}$-prevalence of poor health in country A, $H_{B}$-prevalence of poor health in country $\mathrm{B}, H_{B}^{c f}$ - prevalence of poor health in country B had it had observable factors as in country A (counterfactual).

Counterfactual distributions can be obtained either parametrically (by estimating a series of equations that represent the labour market, income and health) or non-parametrically (by re-weighting) (Fortin et al. 2010). It has been argued that under certain circumstances, the two approaches can be genuine substitutes (Bourguignon et al. 2007). We employ a semi-parametric decomposition technique proposed by DiNardo et al. (1996), which was first used to estimate the effects of institutional and labour market factors on wage inequality. The approach relies on estimating a re-weighting factor $\Psi(X)$ which, when applied to country B, produces a synthetic distribution of the underlying factors mimicking that of country A, but retaining the health function from country B. The resulting counterfactual distribution of health $H_{B}^{c f}$ is then used to decompose the cross-country differences 
in health into the underlying factors. It has been shown than the re-weighting factor $\Psi(X)$ can be constructed from pooled data as a product of the ratios of conditional and unconditional probabilities of each observation belonging to country A and B in the following way:

$$
\Psi_{i}(x)=\frac{\operatorname{Pr}\left(C_{i}=A \mid x\right)}{\operatorname{Pr}\left(C_{i}=B \mid x\right)} \times \frac{\operatorname{Pr}\left(C_{i}=B\right)}{\operatorname{Pr}\left(C_{i}=A\right)},
$$

where $x$ are individual attributes (age, sex, education, etc.), $C_{i}$ denotes country and the conditional probabilities are estimated using a logistic regression. The obtained re-weighting factors $\Psi_{i}(x)$ are interacted with sample weights to account for sampling probabilities and non-response.

The core task relies on constructing a synthetic distribution of health that would prevail in country B had it had a set of observable characteristics as in country A. Country A represents the country with the lowest prevalence of poor health-Ireland - which serves as a benchmark in evaluating country performance in terms of self-assessed health. ${ }^{4}$ Selecting the country at the extreme of the health distribution ensures the largest cross-country variability in health that can be more easily analysed and interpreted. In addition to this, Ireland is a country where health and health inequalities have been studied to a great extent in both national and comparative contexts (see for instance Muntaner et al. 2011, Mackenbach 2006; Nolan et al. 2015), and thus is a robust choice of a reference country.

The underlying question is: "How would the distribution of health in each country look like if it had the distribution of demographic and socio-economic factors as in Ireland, but the health function conditional on these characteristics remained unchanged?" Ultimately, we are interested in using the synthetic distribution to obtain the part of the difference in the prevalence of poor health between two countries that can be explained by the distribution of each of the examined factors.

The proposed approach is well-suited for binary dependent variables and does not require a parametric model to relate the outcome of interest to the explanatory factors. However, cross-country differences in factors like the quality of education and the extent of decommodification provided by the welfare state make it unlikely that the elasticity of health to the examined factors would be the same across countries. Thus, the decomposition approach is path-dependent, meaning that the interpretation of results will differ depending on which country's population is used as a baseline for re-weighting (Fortin et al. 2010). Second, detailed decomposition using the re-weighting approach requires a few additional assumptions (Fortin et al. 2010). Due to the interactions between the underlying factors, the sequence with which the factors are introduced is likely to change the detailed decomposition results.

Some of the proposed solutions to the latter problem are the following: (1) to average the effects of each factor over all possible sequences in the spirit of Shorrocks $(2013 ; 2)$ to employ an additive decomposition approach proposed by Biewen (2012) by calculating marginal effects of each factor and all the possible interaction effects. The drawback of the former approach is that it may mask much of the variation of the effects and their interactions. The results of the latter approach, on the other hand, may be difficult to interpret when many factors are taken into account. Ignoring the interactions and considering marginal effects alone may produce biased estimates when the effect of each factor is obtained

\footnotetext{
4 We find that the prevalence of poor self-assessed health in Ireland is $19 \%$, followed by Greece (26\%) and Luxembourg (27\%).
} 
without controlling for other factors (Gelbach 2009). For example, re-weighting the population of country B according to the income distribution of country A without controlling for education might overestimate the effects of income, if high-income individuals are also individuals with higher educational achievement and thus are more likely to have better health even in the absence of high income.

It has been proposed that the true effect of each factor can be estimated by comparing the following distributions: (1) the counterfactual distribution that would be obtained from country B if all the other factors but factor $x_{k}$ were distributed as in country A; (2) the counterfactual distribution that would prevail in country B if all the observed factors were distributed as in country A (Fortin et al. 2010). In other words, it has been suggested that obtaining conditional rather than marginal distributions of health solves the omitted variable problem in the detailed decomposition. However, the effects obtained using the conditional decomposition approach do not add up to the aggregate effect and are likely to underestimate some of the effects in cases with a large overlap between the explanatory factors.

Alternatively, in the cases where following a particular sequence of factors added one by one can be justified, the sequential decomposition approach might be in order (Fortin et al. 2010). This approach has been applied, for instance, to study the effects of the changes in the characteristics of American youth on the distribution of wages, where the authors first accounted for parental background and then sequentially added variables related to education and transition to the labour market (Altonji et al. 2012). We consider a set of factors that occur one after another in sequence: demographics, education, labour market factors and income. This produces economically interpretable results, whereby interactions are assigned to the preceding factor(s).

Following the aforementioned debate, we first estimate the contributions of the underlying factors using the sequential decomposition approach. Second, we show how the results of the sequential decomposition fare in relation to the results obtained using marginal and conditional decomposition approaches. By doing this, we aim to illustrate the debate on the path dependence problem in the detailed decomposition discussed in Fortin et al. (2010) and see how the results compare under different sequences. Using sequential decomposition approach, the overall difference in the prevalence of poor self-assessed health between Ireland and each analysed country $\left(H_{B}-H_{A}\right)$ is decomposed as follows:

$$
\begin{array}{lr}
H_{B}-H_{A}= & \\
=H_{B}-H_{B}^{d_{A}} & \text { (demographics) } \\
+H_{B}^{d_{A}}-H_{B}^{d_{A} e_{A}} & \text { (education) } \\
+H_{B}^{d_{A} e_{A}}-H_{B}^{d_{A} e_{A} l_{A}} & \text { (labour market factors) } \\
+H_{B}^{d_{A} e_{A} l_{A}}-H_{B}^{d_{A} e_{A} l_{A} i_{A}} & \text { (income) } \\
+H_{B}^{d_{A} e_{A} l_{A} i_{A}}-H_{A} & \text { (other factors) }
\end{array}
$$

\section{(demographics)}

where the term "other factors" contains any differences in self-assessed health between Ireland and the analysed country that cannot be explained by variation in demographics, education, labour market status and income (for example, health differences stemming from differences in healthcare systems, the quality of education, or the extent of decommodification provided by the welfare state). Alternatively, the results for marginal and conditional decomposition approaches are obtained in the following manner (Table 1): 
Table 1 Alternative decomposition sequences

\begin{tabular}{lll}
\hline Marginal effects & Conditional effects & Explanatory factors \\
\hline$H_{B}-H_{B}^{d_{A}}$ & $H_{B}^{e_{A} l_{A} i_{A}}-H_{B}^{d_{A} e_{A} l_{A} i_{A}}$ & Demographics \\
$H_{B}-H_{B}^{e_{A}}$ & $H_{B}^{d_{A} l_{A} i_{A}}-H_{B}^{d_{A} e_{A} l_{A} i_{A}}$ & Education \\
$H_{B}-H_{B}^{l_{A}}$ & $H_{B}^{d_{A} e_{A} i_{A}}-H_{B}^{d_{A} e_{A} l_{A} i_{A}}$ & Labour market factors \\
$H_{B}-H_{B}^{i_{A}}$ & $H_{B}^{d_{A} e_{A} l_{A}}-H_{B}^{d_{A} e_{A} l_{A} i_{A}}$ & Income \\
\hline
\end{tabular}

Like many decomposition approaches available, the semi-parametric decomposition method by DiNardo et al. (1996) ignores the general equilibrium effects and the results do not imply causality (Fortin et al. 2010). However, due to the complex interplay between socio-economic factors and health, the direction of causality is difficult to prove even in longitudinal studies (Goldman 2001). Decomposition methods help to uncover the quantitative strength of these relationships and suggest factors to be investigated in depth (Fortin et al. 2010).

\section{Data}

Micro-econometric decomposition approach requires detailed data on health and related socio-economic factors. We use the European Statistics on Income and Living Conditions (EU-SILC), a micro-level survey that contains information on living standards, housing, social exclusion, labour market participation, and health. EU-SILC provides both crosssectional data collected every year and panel data for the duration of 4 years for all EU member states and Iceland, Norway, Switzerland, and Turkey. EU-SILC data is one of the major data sources in Europe for cross-national research and social reporting in the EU, with large country samples and harmonised data collection concepts, guidelines and procedures. The richness of the dataset in providing information on demographic and socioeconomic factors and availability of health information are some of the main advantages of using it to understand the sources of health inequality in the EU.

We use the cross-sectional dataset from year 2010 because it was a year marked by substantial economic pressures and policy shifts due to the global financial crisis that reached Europe in 2008. A significant increase in unemployment, fluctuations in market income and growing pressures on social welfare and healthcare systems in many EU countries introduced more variability in the factors responsible for good health, which can be more easily captured using the decomposition approach.

EU-SILC collects information on three variables related to health status: self-assessed health ( 5 categories from very good to very bad health), chronic morbidity and limitations in activities due to health issues. The dependent variable in this study is self-assessed health (SAH), which is one of the most commonly used indicators of health in social research. As a measure of health available in many household surveys, it is considered a good proxy for both psychological and physical health (Jylhä et al. 1998). It is not only found to be a reliable indicator of the current health status that outperforms both more and less detailed questions (Lundberg and Manderbacka 1996), but also a good predictor of mortality (Idler and Benyamini 1997), functional and cognitive impairment later in life (Bond et al. 2006) and lifestyle-related health status (Yamada et al. 2012). Its wide availability in household surveys, global nature and the ability to predict the onset of diseases are among the main factors making the self-assessed health indicator attractive for research on 
Table 2 Explanatory factors

\begin{tabular}{lll}
\hline Explanatory factors & Variables & Values \\
\hline Demographics & Age & $30-79$ \\
& Gender & Male, female \\
& Marital status & Married, not married \\
& Country of birth & Local, foreign-born \\
Education & Highest ISCED level attained & Tertiary, upper secondary, other \\
Labour market factors & Labour market status & Employed/student, self-employed, unemployed, \\
& & retired, disabled, inactive \\
& Occupation & 10 categories (incl. people with no work experi- \\
& & ence) \\
Income & Difficulty in making ends meet & Yes/no \\
& Relative income & 5 categories \\
\hline
\end{tabular}

socio-economic inequality. On the other hand, one of the challenges in using self-assessed health is the potential variation in response patterns across different countries and sociodemographic groups (Bago d'Uva et al. 2008; Crossley and Kennedy 2002; Lindeboom and van Doorslaer 2004). Hence, it is important to take into consideration the social context when assessing differences in self-assessed health across societies (Sen 2002). In addition to this, problems with aggregation arise due to the ordinal nature of the self-assessed health indicator. Normative decisions used to cardinalise the values may be responsible for a lot of heterogeneity in the cross-country comparisons of health and health inequality (Costa-Font and Hernández-Quevedo 2013). Due to this, we will limit the analysis to two categories: good health, which includes good and very good response categories, and poor health, which comprises very bad, bad and fair health. Prevalence of poor self-assessed health is used as an indicator of population health, which denotes the population share reporting poor health in each country.

Indicators of demographic characteristics, education, labour market factors and income are used to explain variation in population health across countries (Table 2). Demographic factors include age, sex, marital status (married and not married) and the country of birth (local or foreign born). Education is measured by the highest level attained using the ISCED-97 classification, grouped into three categories - lower secondary or below, ISCED levels 0-2; upper secondary and post-secondary non-tertiary, ISCED levels 3-4; and tertiary education, ISCED level 5. Labour market factors are represented by two sets of variables, namely: self-defined economic activity status (employed/student, ${ }^{5}$ self-employed, unemployed, retired, disabled and inactive) and occupational grade measured using the ISCO-88 classification (10 categories from legislators to elementary occupations, including a category for individuals with no work experience). To account for the differences in the living standards, two sets of measures are used: an objective measure denoting the individual's position in income distribution in relation to country's median income (5 categories obtained by dividing the Irish income distribution into quintiles, ${ }^{6}$ ) and a subjective

\footnotetext{
5 The total number of students in the sample of adults above 30 years $(0.18 \%)$ was insufficient for including students as a separate group. Due to the comparability to employed individuals with respect to age and selfassessed health status, the two categories have been grouped.

6 The resulting thresholds dividing individuals into 5 income groups were $0.64,0.86,1.15$ and 1.57 of the median equivalised household disposable income in each country.
} 
measure of reporting difficulties in making ends meet (with difficulty and great difficulty). A self-assessed measure is considered for two reasons. First, income may not reflect purchasing power differences across regions and the extent of relative deprivation (Wilkinson 1992). Second, a subjective measure is a good proxy for the stress related to financial strain that might have an indirect effect on health, which has been largely ignored in the literature (Arber et al. 2014).

To ensure cross-country comparability and avoid potential bias due to non-response, we select countries with less than $20 \%$ non-response rates for self-assessed health and the explanatory factors. Notably, we found a large variation in response rates to the question of self-assessed health by country (Table 5 in the Appendix). Most of the countries that largely rely on national registers to collect information (excluding Latvia and Ireland) have non-response rates for self-assessed health ranging between $44.9 \%$ in the Netherlands to $60.1 \%$ in Slovenia. These countries collect the remaining information by interviews of selected respondents. It is advised to view the cross-country results between countries with different modes of data collection with caution, in particular in the case of variables with high non-response (Katchadourian and Cambois 2013). Therefore, we exclude these countries from our sample. We also exclude Romania due to the differences in the coding of the occupational grades (ISCO-08 classification cannot be mapped into ISCO-88 without a loss of information) and the UK due to the quality concerns over the education variable, ${ }^{7}$

The sample is limited to individuals of 30-79 years old in order to avoid potential bias resulting from relatively larger non-response among the younger and older individuals. Missing out on some of the economically active population might lead to an overestimation of poor health among the young, whereas non-response among the old-age individuals due to inability to respond to questions might underestimate the extent of activity limitations among the elderly (Katchadourian and Cambois 2013). Finally, in order to have a balanced sample throughout the decomposition, we drop the observations whose data are missing for any of the explanatory variables. We find no significant differences with respect to the prevalence of poor self-assessed health between the initial and the final sample (Table 6 in the Appendix). However, it is unknown whether any bias may result for countries with some missing data for self-assessed health (namely Czechia, Lithuania, and Estonia). Therefore, results for these countries should be viewed with some caution.

Finally, to take into account some of the regional differences with respect to economic and social conditions, we classify countries into three regions: Western European countries with well-established social welfare states, Southern European countries with a mix of extensive and limited social welfare provisions and important role of family in social care and Central and Eastern European (CEE) countries that have undergone massive liberal reforms and are struggling with ensuring adequacy in social welfare provisions (Table 3). Western countries consist of mainly Bismarckian welfare states with more generous status-differentiating social welfare provisions and Ireland characterised by a larger role of the market and means-tested social benefits (Eikemo et al. 2008a). While these typologies reflect some of the variation in terms of economic performance and social welfare provision, they are by no means universal and mask some cross-country variation, especially with respect to austerity policies undertaken in response to the 2008 economic crisis

\footnotetext{
7 In EU-SILC 2010, the education variable in the UK had an $11.2 \%$ non-response and the low education category was largely underrepresented. According to the Labour Force Survey (EUROSTAT 2010b) the share of individuals with lower than upper secondary education in the 15-64 age group was $25.7 \%$, compared to only $15.7 \%$ in the EU-SILC data.
} 


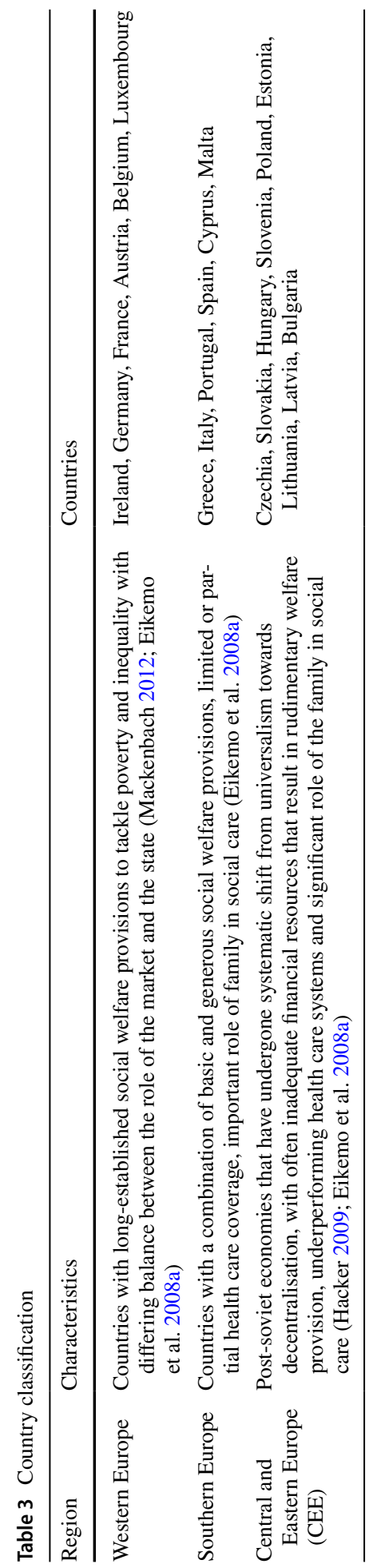


(Quaglio et al. 2013). Grouping countries into regions will not allow us to directly estimate regional differences in the results, but may suggest whether shared institutional, cultural and economic factors shape population health in a similar way.

\section{Country-Level Characteristics and Self-Assessed Health}

In this section we discuss how self-assessed health in the EU varies with other countrylevel indicators of health and healthcare performance, income, education and labour market situation. By doing so, we aim to provide a context for interpreting decomposition results.

Analysis of differences in population health cannot be undertaken without considering the performance of healthcare systems, which can be summarised by indicators of healthcare coverage, funding and health outcomes (Table 4). First, some cross-country variation exists in terms of population coverage of health insurance, which ranges from $83 \%$ in Cyprus to full coverage in half of the countries analysed. Services covered under the basic health insurance usually include doctor visits, medical examinations and hospital care (OECD 2012b). In countries where health insurance is not mandatory, individuals may seek healthcare at their own expense. However, coverage is not a perfect indicator of healthcare access due to the differences in the benefits covered under health insurance and cost-sharing arrangements, which can range from full reimbursement to user fees (OECD $2012 \mathrm{~b}$ ). The share of out-of-pocket payments is a good indicator of accessibility to healthcare services provided by the state. These include co-payments for health services and private providers, pharmaceuticals and in some cases informal payments incurred by the patients. Some regional patterns emerge: Western European countries have on average the lowest share of out-of-pocket payments (from $7.3 \%$ in France to $19.4 \%$ in Belgium), compared with Southern and Central and Eastern European region where the rates vary from 14.9\% in Czechia to $43.4 \%$ and $49.4 \%$ in Bulgaria and Cyprus, respectively. These figures go in line with healthcare expenditure per capita and as a share of GDP, which are the highest in the Western European countries and the lowest in the CEE region.

Variation in healthcare funding and cost-sharing arrangements seem to translate directly into differences in health achievement. Mortality rates per 100,000 population suggest that Western and Southern European countries outperform than Central and Eastern European countries with respect to population health. For example, age-adjusted mortality rates in Lithuania are almost twice as large compared with Spain. A similar picture emerges from the health policy performance scores proposed by Mackenbach et al. (2013). The performance scores are composed of 27 indicators from 11 areas (tobacco, alcohol, food and nutrition, fertility, pregnancy and childbirth, child health, infectious diseases, hypertension, cancer screening, mental health, road traffic safety and air pollution) and include performance, outcome and impact indicators, such as country's policy score on Tobacco Control Scale, smoking prevalence rate and lung cancer mortality rate. Western countries show above-average performance, with France and Austria having the highest scores among the analysed countries. From the Southern European countries, Malta ranks best with a performance score similar to the one in Germany, followed by Spain, Cyprus and Italy. All the Central and Eastern European countries have below-average performance. Bulgaria and Latvia have the lowest performance scores, and they are also among the three countries where more than $15 \%$ of the population reports unmet need in healthcare and over onethird of costs are covered by the out-of-pocket payments. Chronic illness and limited activity, on the other hand, seem to be rather evenly distributed across regions. 


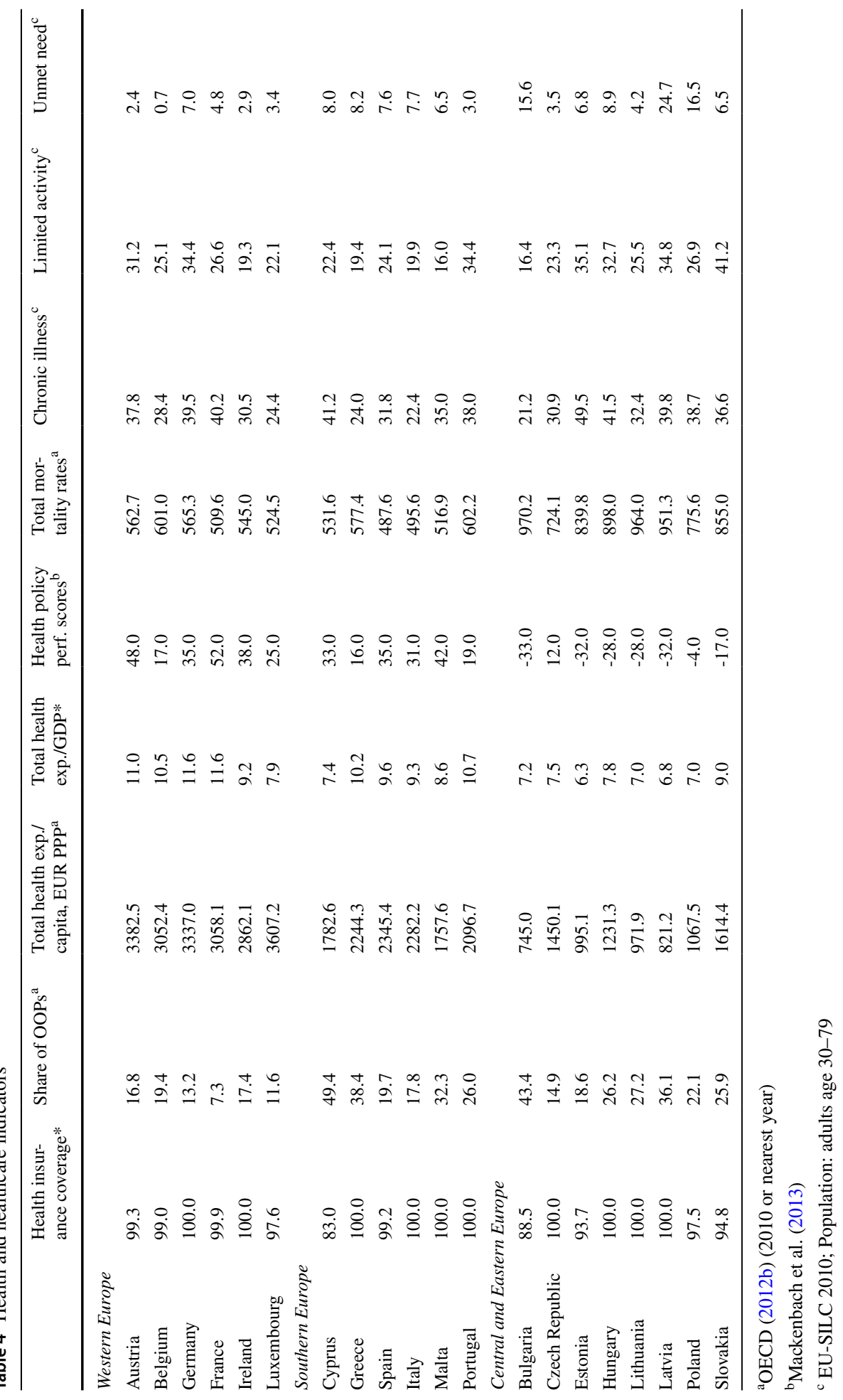




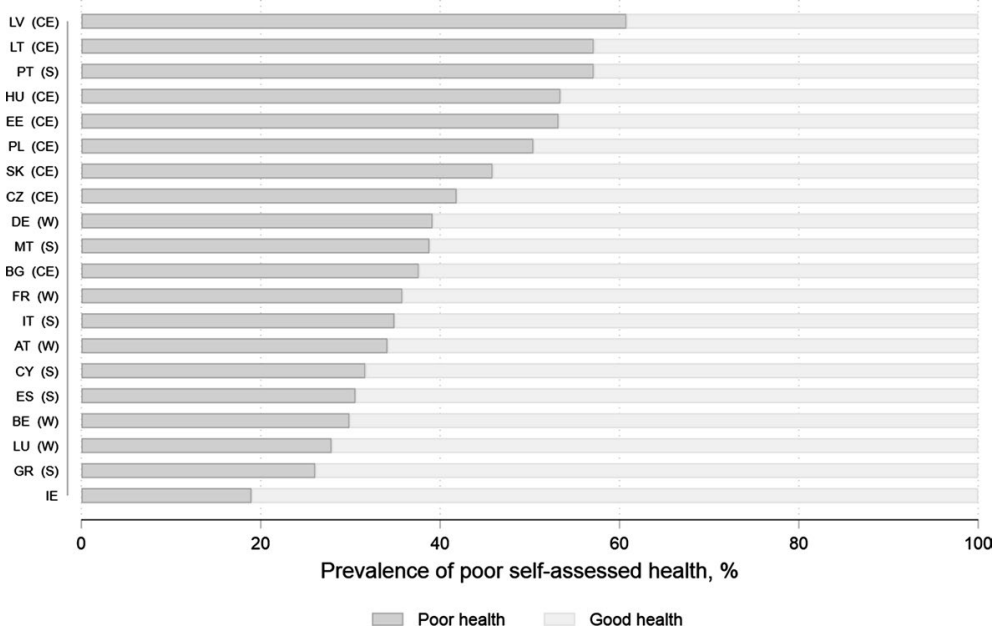

Fig. 1 Prevalence of poor self-assessed health in the EU. Notes CE-Central and Eastern Europe, S-Southern Europe, W-Western Europe Source: EU-SILC 2010, population: adults age 30-79
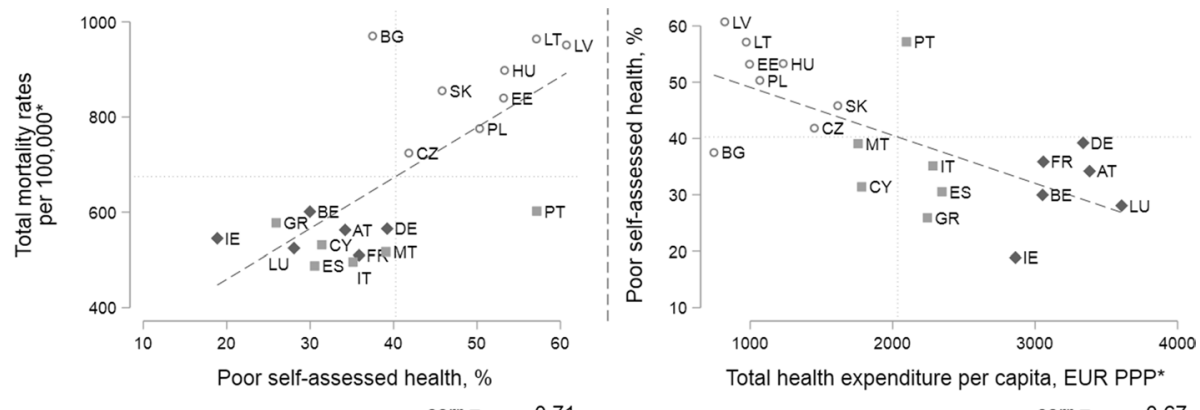

corr $=0.71$

corr $=\quad-0.67$

- Western Europe $\quad$ Southern Europe $\circ$ Central and Eastern Europe - - Linear fit

Fig. 2 Self-assessed health, all-cause mortality and healthcare expenditure Sources: EU-SILC 2010 (adults age 30-79), *OECD (2012) (2010 or nearest year)

The health and healthcare indicators reviewed so far suggest a clear division between the East and the West. This phenomenon, known as the East-West divide (Carlson 2004; Nolte and McKee 2004; Zatonski and Bhala 2012), has been attributed to the recent political history, differences in economic performance, behaviours, health policies and culture (Mackenbach 2014). This division is also clear in the distribution of the prevalence of poor health (Fig. 1). Most of the CEE countries have above average prevalence of poor health ranging from $60.8 \%$ in Latvia to around $38 \%$ in Bulgaria. No clear rankings can be made between the Southern and Western European regions. Surprisingly, Portugal is one of the countries with a very large share of individuals reporting poor health, while Greece stands out as one of the countries with the best subjective health, even though both countries have comparable mortality rates and national income (see Fig. 2 below and Fig. 6 in the Appendix). The most striking is the range of the prevalence of poor self-assessed health: 
for example, the Irish population is three times less likely to report poor health than than of Latvia (19\% compared with $60.8 \%$ ).

We find that high levels of poor self-assessed health are good predictors of overall mortality rate, as previously suggested (Idler and Benyamini 1997). However, the relationship is much less clear for countries with below-average prevalence of poor health, namely Western and Southern European countries (Fig. 2). In addition, two countries emerge as outliers: Bulgaria with one of the highest mortality rates but around average rates of poor health and Portugal with a high prevalence of poor health and around average mortality rate. The results for Bulgaria are particularly surprising: it is a country which ranks poorly in terms of both healthcare and health achievement, namely low funding, high out-of-pocket payments, low health performance score and high reporting of unmet need in healthcare.

Overall, country-level indicators on healthcare performance are somewhat predictive of the prevalence of poor self-assessed health in the EU, yet significant unexplained variation remains. Total healthcare expenditure seems to matter most for self-assessed health out of all the macro indicators analysed, including GDP per capita (see Fig. 2 below and Fig. 6 in the Appendix). However, healthcare expenditure is a good predictor of self-assessed health only in the Central and Eastern Europe, but not in other regions. Southern European countries seem to be better at achieving good self-assessed health with lower total spending and higher out-of-pocket payments. The descriptive results indicate that individual-level factors may play a role in explaining differences in population health. It has been proposed that such factors may account for more than half of the cross-country variation in health (Olsen and Dahl 2007).

Table 7 in the Appendix shows the distribution of demographics, education, income and labour market factors across countries. In terms of the demographic structure, Ireland has a relatively younger population, especially compared with other Western European countries. Since young individuals are less likely to report poor health than older individuals and the distribution of other demographic factors does not vary much across countries, the effects of demographics in explaining health inequality are likely to be more pronounced in the Western Europe. With regard to the labour market factors, it is hard to predict what can be expected: Ireland has a rather large share of the unemployed and inactive who tend to report worse health than employed individuals, but it has a higher proportion of individuals concentrated at higher occupational grades.

At the first glance, the effects of education on the prevalence of self-assessed health are not entirely clear. Ireland stands out as one of three countries with nearly a third of the adults of ages 30-79 with a university degree (next to Belgium and Estonia), but it also has a relatively large share of individuals with low education level (about 40\%, compared with 12-30\% in Austria, Germany and all the CEE countries). Given the high share of individuals with low educational attainment in Ireland compared with most of the Western and CEE countries, it is unlikely that education will provide a conclusive explanation why Ireland has better selfassessed population health than countries in these regions. On the other hand, education may be important in explaining some of the excess poor health in the Southern European countries, because these countries have a less favourable distribution of education levels compared with Ireland irrespective of the cutoff point (in particular in Greece, Italy, Spain, and Portugal). There, the share of individuals with less than upper secondary education varies between $44.4 \%$ in Greece and $78.6 \%$ in Portugal (compared with $27 \%$ in Ireland). In addition, we can expect to explain more of the excess poor health for countries with a higher elasticity of health to education, such as Portugal, where the odds ratio for reporting poor health among individuals with 
tertiary education compared with individuals with up to lower secondary education is 0.39 as opposed to up to 0.72 in countries like Slovakia (Table 9 in the Appendix). ${ }^{8}$

Finally, income and self-reported difficulties in making ends meet are rather unevenly distributed across and within regions. Overall, Western European countries tend to report fewer difficulties in making ends meet than Ireland and other analysed countries, which makes it unlikely that income will be an important factor in explaining cross-country health inequalities for these countries. Southern and CEE countries, on the other hand, are on average more likely to report difficulties in making ends meet, and most of the countries also have a larger share of individuals concentrated in lower income categories compared with Ireland. In particular, Greece, Cyprus and Malta among the Southern European countries and Bulgaria, Hungary, and Latvia among the CEE countries are the countries where income may be important in explaining poorer self-assessed health. However, the role of each factor will depend on the interactions between different explanatory factors. We discuss the decomposition results in the next section.

\section{Decomposition Results}

This section describes the semi-parametric decomposition results for explaining cross-national differences in the prevalence of poor self-assessed health across EU countries. In the first part, we present the aggregate effects and sequential decomposition effects, whereby the effect of each factor is obtained by sequentially adding one factor after another and estimating the differences between the two counterfactual distributions. In the second part, we discuss the results obtained using two alternative decomposition sequences: marginal decomposition, whereby the effect of each factor is obtained without controlling for other factors; and conditional ('last-in') approach where the effect of each factor is evaluated after conditioning for all other factors. The last two approaches are complete opposites; knowing that the factors analysed are likely to have a large overlap and interaction effects, we expect the results to differ depending on the sequence chosen. By comparing the three approaches, we aim to shed some light on how the effects perform under different decomposition sequences, and whether some effects are more robust than others under different scenarios. The sequential decomposition results are expressed as a share of excess poor health (measured as the prevalence of poor selfassessed health) in each comparison country compared with Ireland.

As expected, we find considerable regional variation in the aggregate decomposition results (Fig. 3). The dark bars show how much of excess poor health in each country compared with Ireland can be attributed to differences in demographics, education, labour market status and income. The lighter bars show the part of excess poor health which could not be explained by the analysed factors and that may arise due to other factors, such as differences in the healthcare provision. The examined factors taken together perform well in explaining excess poor health in most of the Southern European and CEE countries. For example, in Greece, where the rate of reporting poor health is 7.1third of the excess poor health $(2.7 \mathrm{pp})$. However, these factors fail to explain much of the variation between Ireland and other Western European countries. Contrary to the expectation, the prevalence of poor health would be even higher in Western European countries, if they had the distribution of demographic and socioeconomic factors as in Ireland. This finding might indicate the presence of cultural differences

${ }^{8}$ Large education-related health inequalities in Portugal are also found in von dem Knesebeck et al. (2006). 


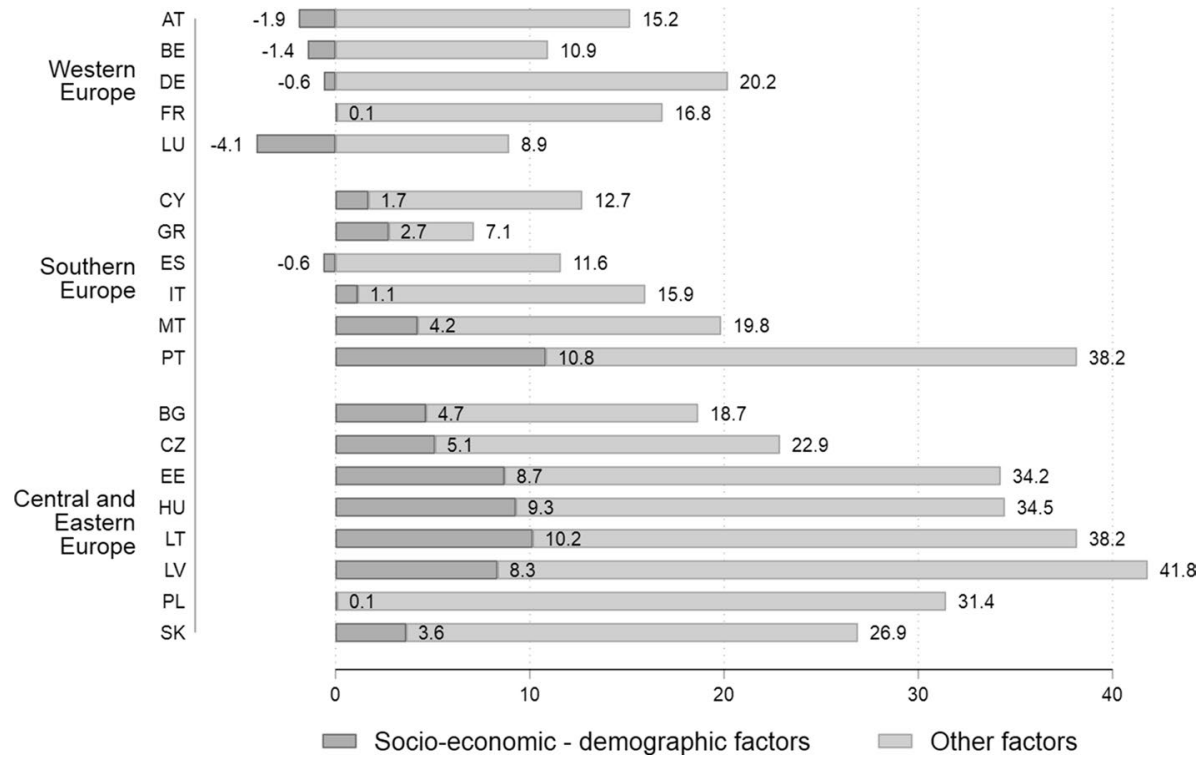

Fig. 3 Aggregate decomposition results (comparison country-Ireland). Notes: Positive coefficients measure how much of excess poor health (in p.p.) is explained when all the observed factors are imported from Ireland. Negative coefficients show an increase in inequality after accounting for all the factors.

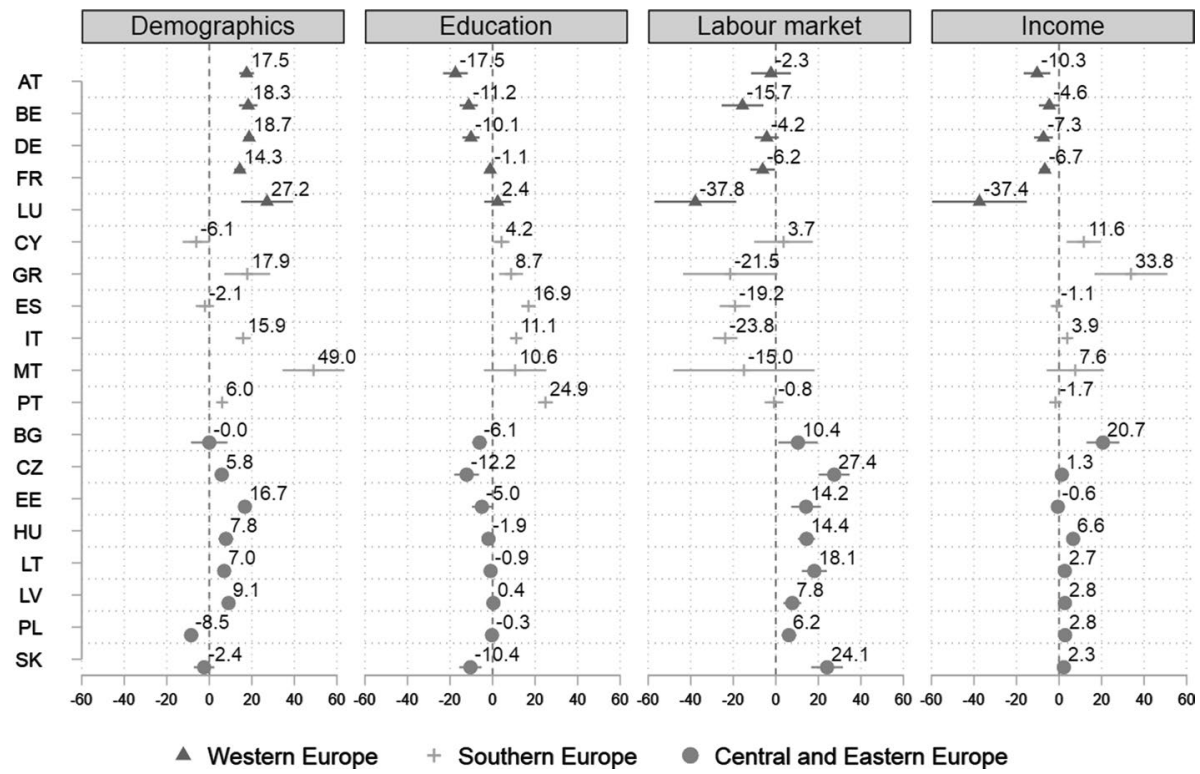

Fig. 4 Sequential decomposition results (comparison country-Ireland). Notes: Positive coefficients represent the share of the excess poor health (in \%) compared with Ireland accounted for by each factor. Negative coefficients show an increase in inequality in each country after importing factors from Ireland. Bootstrapped standard errors for $95 \%$ confidence bands ( 500 replications, stratified by age and sex) are shown by horizontal lines 
in evaluating one's health across countries: the results may have differed if an objective measure of health was decomposed. However, we are more confident that the differences in selfassessed health between Ireland and Central and Eastern European countries are more robust because they reflect the East-West divide in objective health measures, such as the prevalence of heart disease (Olsen and Dahl 2007).

Regional clustering is also evident in the sequential decomposition results (Fig. 4). Even though the factors taken together could not explain differences in self-assessed health between Ireland and the Western European countries, demographics account for 14.3-27.2\% of the cross-country gap. Significant positive effects of population structure are found for most other European countries, in particular Malta (49\%), though results within the Southern European and CEE regions are less consistent. The effects are largely driven by the age structure: Ireland has a relatively large population of individuals below 40 years of age, who report considerably better health in many countries compared with older individuals (Table 8 in the Appendix). However, we find a significant negative effect of demographics in Poland, which means that if Poland had Ireland's demographic structure, the prevalence of poor health would be $8.5 \%$ higher (hence, the gap between the countries would increase). The result may be driven by the large differences in the share of individuals born abroad between Poland and Ireland (1\% and $13.9 \%$ respectively, see Table 7 in the Appendix), who report higher odds of having poor health in Poland than the natives (Table 8 in the Appendix).

The role of each of the socio-economic determinants is estimated by adding factors one after another in a sequence. It means that the interaction effects are accounted for by the preceding factor(s). After controlling for demographics, differences in education account for up to onefourth of the health gap between the examined countries and Ireland. As expected, we find the largest effects of education on excess poor heath for Portugal (24.9\%), where the share of individuals with at least upper secondary education among individuals of ages 30-79 is slightly above $20 \%{ }^{9}$ compared with $60 \%$ in Ireland. Somewhat smaller but significant effects are found for other Southern European countries: Spain, Italy, Greece, Malta and Cyprus (4.2-16.9\%). Labour market factors (economic activity status and occupational grade), on the other hand, play an important role in explaining health inequalities between Ireland and the CEE region, but not in other countries. The effects are most pronounced in Czechia (27.4\%) and Slovakia (24\%), and somewhat less pronounced in Hungary, Bulgaria, the Baltic states and Poland (6.2\% to $18 \%$ ). The contributions to the excess poor health accounted for by income (income position with respect to the median and inability to make ends meet) are most pronounced in Greece and Bulgaria, where it accounts for $33.7 \%$ and $20.6 \%$ of the overall difference, respectively. Similar but slightly smaller effects are found for Cyprus (11.6\% of the overall gap) and Hungary (6.6\% of the gap). Mostly positive but sometimes lacking significance are the effects of income on the health gap between Ireland and other CEE countries. This is not surprising given the high interaction of income with education and labour market status (Lahelma et al. 2004), which have been accounted for before estimating the effects of income.

When comparing sequential decomposition results with the results obtained using marginal and conditional decomposition approaches, we find that labour market factors and education remain important for explaining excess poor health in the CEE and Southern European countries, respectively (Fig. 5). Income effects tend to decrease after taking into account other factors, but some countries (in particular, Bulgaria, Greece, Hungary, and Cyprus) maintain stable effects irrespective of the decomposition order.

\footnotetext{
9 Estimates for the population aged 25-64 in 2010 are about 33\% based on SILC and OECD data (OECD 2012a).
} 

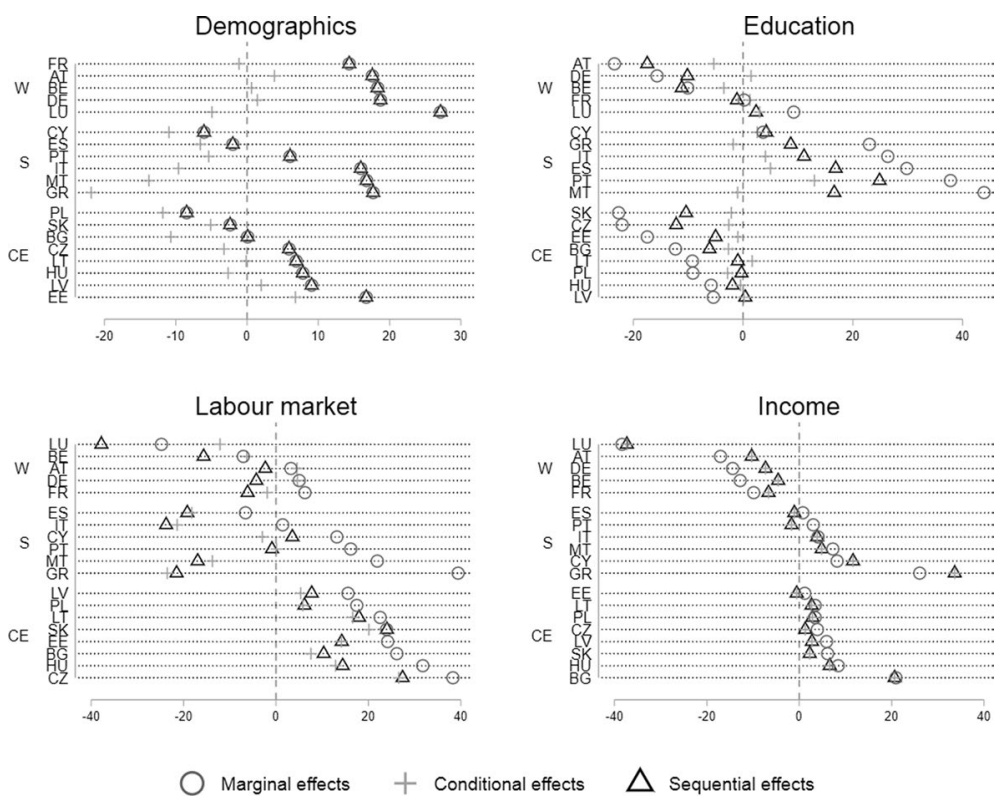

Fig. 5 Comparison of marginal, sequential and conditional decomposition effects. Notes: W-Western Europe, $\mathrm{S}$ - Southern Europe, $\mathrm{CE}$ - Central and Eastern Europe

Overall, the dispersion of the results based on the decomposition order indicates the presence of interactions between population structure, education and labour market factors. For example, it may be that younger cohorts are better educated and have more upto-date labour market skills, which helps them better succeed in the labour market. We also find that interactions between examined factors are not uniform across countries, and therefore could be studied in detail, for example, using the additive decomposition approach proposed by Biewen (2012).

Overall, when we introduce the factors one by one in a sequential manner, we find that differences in the population structure explain the largest part of the health inequality for the Western European countries, education and income-for Southern European countries, while the biggest role of labour market factors is played in the Central and Eastern European countries. In addition to this, we find that conditioning on all the other factors has a reducing effect on the decomposition effects but most of the effects remain significant irrespective of the decomposition sequence. This is not surprising: when we control for all but one factor to estimate conditional decomposition effects, we are potentially discarding interactions between different factors, and when we estimate marginal decomposition effects, we are assigning the interactions to each of the examined factors. Therefore, it is likely that the true effect lies somewhere in between.

\section{Conclusion}

Recent studies have highlighted the importance of socio-economic factors in shaping health inequalities and population health. However, little is known how these factors shape crosscountry health inequality. In this paper, we set out to shed light on how demographics, 
education, labour market factors and income explain the variation of the prevalence of poor self-assessed health across the EU, and to find out whether there are any regional differences in the role of different factors in explaining cross-country variation in population health. In order to do so, we compared the distribution of health between each analysed country and the country with the lowest prevalence of poor self-assessed health-Ireland in a number of pair-wise comparisons, and decomposed the health differential into the differences in the distribution of explanatory factors. In addition to this, we tested how the detailed decomposition results compared under different decomposition sequences in order to reflect on the path dependence problem in the proposed decomposition approach and test the robustness of the results.

Overall, we find that the examined factors taken together explain up to one-third of health differences between Ireland and Southern and Central and Eastern European countries. The educational achievement gap in the Southern European countries is responsible for some of the excess poor health when compared to the Irish health distribution. In the Central and Easter European countries, on the other hand, distribution of income and labour market factors explain the major part of the excess poor health due to differences in socio-economic characteristics, while high levels of education seem to have a protective role on population health. Even though the size of the effect changes depending on the order of the decomposition, they remain positive and significant.

On the other hand, we were not able to explain the observed differences in population health between Ireland and other Western European countries. We find that apart from the less favourable age structure, other Western European countries mostly have more favourable distributions of education, labour market factors and income when compared to Ireland. The fact that these countries have better performance in other examined health indicators suggest potential cross-country differences in the reporting of self-assessed health. Additionally, other factors may play a role in explaining differences in self-assessed health between Ireland and other Western European countries that are outside the scope of this paper, such as differences in the environmental and social factors, access to public services, behaviours and culture.

The results of this study confirm that socio-economic and demographic factors play a significant role in explaining the differences in population health across the EU. Increasing educational attainment and fostering policies aimed at breaking the link between labour market status, income and health are some of the ways to improve population health and reduce cross-country health inequality.

Open Access This article is licensed under a Creative Commons Attribution 4.0 International License, which permits use, sharing, adaptation, distribution and reproduction in any medium or format, as long as you give appropriate credit to the original author(s) and the source, provide a link to the Creative Commons licence, and indicate if changes were made. The images or other third party material in this article are included in the article's Creative Commons licence, unless indicated otherwise in a credit line to the material. If material is not included in the article's Creative Commons licence and your intended use is not permitted by statutory regulation or exceeds the permitted use, you will need to obtain permission directly from the copyright holder. To view a copy of this licence, visit http://creativecommons.org/licenses/by/4.0/.

\section{Appendix}

See Tables 5, 6, 7, 8 and Fig. 6. 
Table 5 Non-response in EU-SILC 2010

\begin{tabular}{|c|c|c|c|c|c|}
\hline \multirow[t]{2}{*}{ Country } & \multicolumn{5}{|c|}{ Variable non-response, $\%$} \\
\hline & $\begin{array}{l}\text { Self-assessed } \\
\text { health }(\%)\end{array}$ & Education (\%) & Occupation (\%) & $\begin{array}{l}\text { Difficulty making } \\
\text { ends meet }(\%)\end{array}$ & $\begin{array}{l}\text { At least one } \\
\text { variable (\%) }\end{array}$ \\
\hline \multicolumn{6}{|c|}{ Selected countries } \\
\hline AT & 0.1 & 0.0 & 0.6 & 0.1 & 0.8 \\
\hline $\mathrm{BE}$ & 1.2 & 1.4 & 0.2 & 0.0 & 1.8 \\
\hline BG & 0.2 & 0.2 & 0.9 & 0.0 & 0.9 \\
\hline $\mathrm{CY}$ & 0.0 & 0.0 & 0.7 & 0.0 & 0.7 \\
\hline $\mathrm{CZ}$ & 14.6 & 0.0 & 0.4 & 0.0 & 14.9 \\
\hline $\mathrm{DE}$ & 0.5 & 0.5 & 0.5 & 0.1 & 0.6 \\
\hline $\mathrm{EE}$ & 18.5 & 0.9 & 0.6 & 0.0 & 19.0 \\
\hline GR & 0.5 & 0.5 & 1.6 & 0.0 & 1.6 \\
\hline ES & 1.2 & 1.3 & 2.1 & 0.0 & 2.3 \\
\hline FR & 0.6 & 0.3 & 2.4 & 0.0 & 2.9 \\
\hline $\mathrm{HU}$ & 0.3 & 0.0 & 1.0 & 0.1 & 1.4 \\
\hline IE & 0.0 & 1.7 & 0.9 & 0.0 & 2.6 \\
\hline IT & 0.9 & 0.0 & 0.7 & 0.0 & 1.7 \\
\hline LT & 11.7 & 0.3 & 0.3 & 0.0 & 12.1 \\
\hline LU & 0.1 & 0.4 & 0.3 & 0.9 & 1.7 \\
\hline LV & 1.3 & 0.8 & 0.2 & 0.0 & 1.5 \\
\hline MT & 0.1 & 0.0 & 1.2 & 0.5 & 1.7 \\
\hline PL & 5.6 & 5.6 & 0.4 & 0.0 & 6.0 \\
\hline PT & 0.6 & 0.7 & 0.9 & 0.1 & 1.2 \\
\hline SK & 0.3 & 0.1 & 0.5 & 0.0 & 0.8 \\
\hline \multicolumn{6}{|c|}{ Omitted countries } \\
\hline \multicolumn{6}{|c|}{ Reason: high non-response in the self-assessed health variable } \\
\hline DK & 48.8 & 1.3 & 2.8 & 0.0 & 50.8 \\
\hline FI & 49.0 & 1.1 & 0.7 & 0.6 & 50.0 \\
\hline IS & 52.4 & 1.5 & 0.7 & 1.6 & 53.0 \\
\hline NL & 44.9 & 0.9 & 5.2 & 0.3 & 48.4 \\
\hline NO & 47.5 & 2.2 & 2.2 & 0.2 & 49.5 \\
\hline SE & 48.6 & 0.5 & 2.2 & 2.9 & 50.0 \\
\hline SI & 60.1 & 0.0 & 3.3 & 0.0 & 61.1 \\
\hline \multicolumn{6}{|c|}{ Reason: high non-response in the explanatory variables } \\
\hline RO & 0.2 & 0.2 & 100.0 & 0.0 & 100.0 \\
\hline UK & 1.5 & 11.2 & 3.2 & 0.5 & 13.3 \\
\hline
\end{tabular}

Data: EU-SILC 2010, sample: individuals 30-79 years of age 
Table 6 Sample size and the prevalence of poor self-assessed health in the initial and final sample (adults 30-79 years old)

\begin{tabular}{|c|c|c|c|c|}
\hline \multirow[t]{2}{*}{ Country } & \multirow{2}{*}{$\begin{array}{l}\text { Final } \\
\text { sample size } \\
\text { (N) }\end{array}$} & \multicolumn{3}{|c|}{ Poor self-assessed health (\%) } \\
\hline & & $\begin{array}{l}\text { Initial } \\
\text { sample } \\
(\%)\end{array}$ & Final sample (\%) & Difference (\%) \\
\hline AT & 8810 & 34.2 & 34.2 & 0.0 \\
\hline $\mathrm{BE}$ & 8788 & 30.0 & 29.9 & 0.1 \\
\hline BG & 10986 & 37.5 & 37.6 & -0.1 \\
\hline CY & 6346 & 31.4 & 31.7 & -0.3 \\
\hline $\mathrm{CZ}$ & 11905 & 41.8 & 41.9 & -0.1 \\
\hline $\mathrm{DE}$ & 19417 & 39.2 & 39.2 & 0.0 \\
\hline EE & 6338 & 53.2 & 53.2 & 0.0 \\
\hline GR & 11157 & 25.9 & 26.1 & -0.2 \\
\hline ES & 22954 & 30.5 & 30.6 & -0.1 \\
\hline FR & 15500 & 35.9 & 35.8 & 0.1 \\
\hline $\mathrm{HU}$ & 15388 & 53.3 & 53.4 & -0.1 \\
\hline IE & 6681 & 18.9 & 19.0 & -0.1 \\
\hline IT & 30625 & 35.1 & 35.1 & 0.0 \\
\hline LT & 7741 & 57.1 & 57.1 & 0.0 \\
\hline LU & 7729 & 28.1 & 27.9 & 0.2 \\
\hline LV & 9387 & 60.7 & 60.8 & -0.1 \\
\hline MT & 6694 & 39.1 & 38.8 & 0.3 \\
\hline PL & 21060 & 50.3 & 50.4 & -0.1 \\
\hline PT & 8647 & 57.2 & 57.1 & 0.1 \\
\hline SK & 9606 & 45.8 & 45.9 & -0.1 \\
\hline
\end{tabular}

Data: EU-SILC 2010, sample: individuals 30-79 years of age 


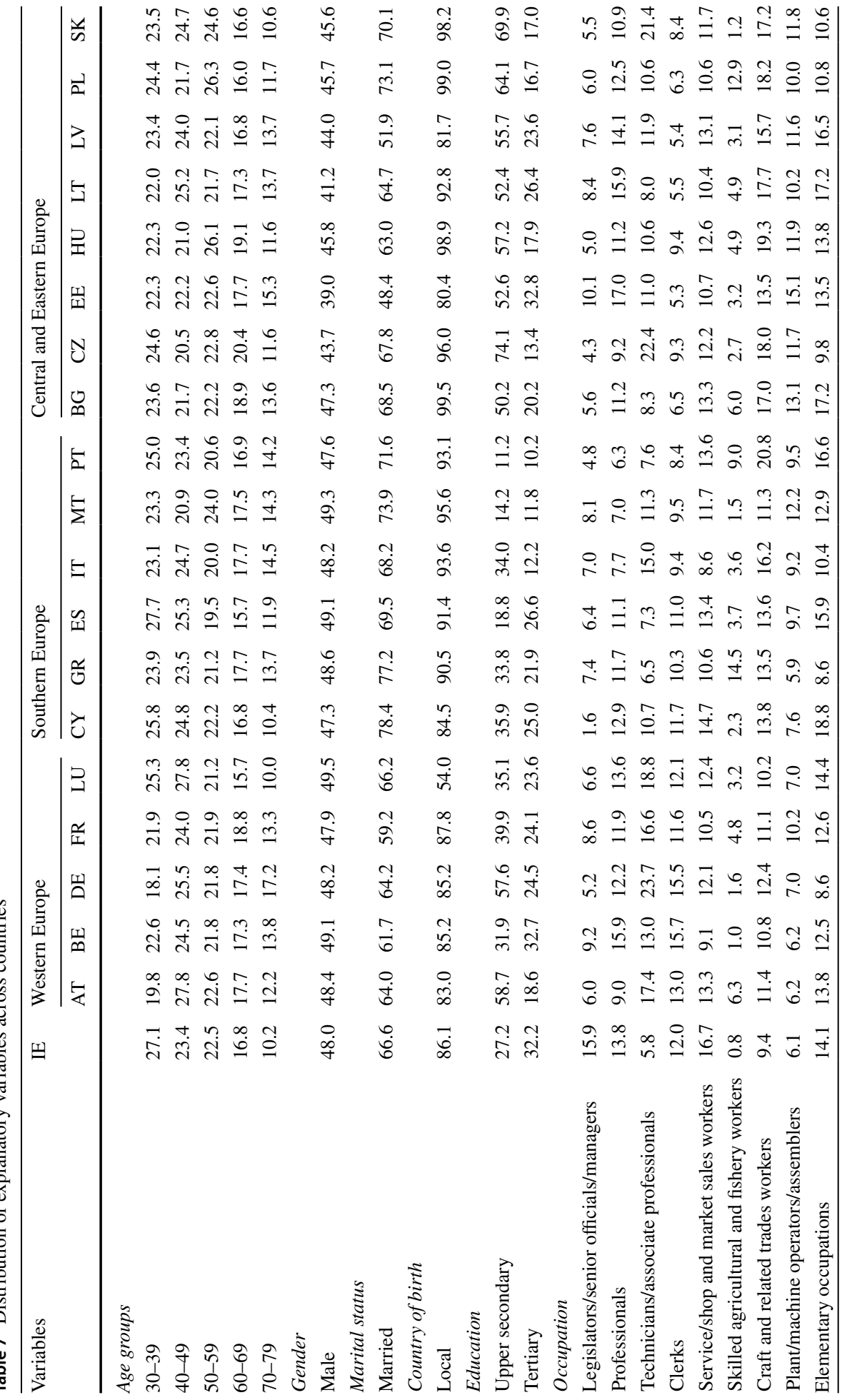




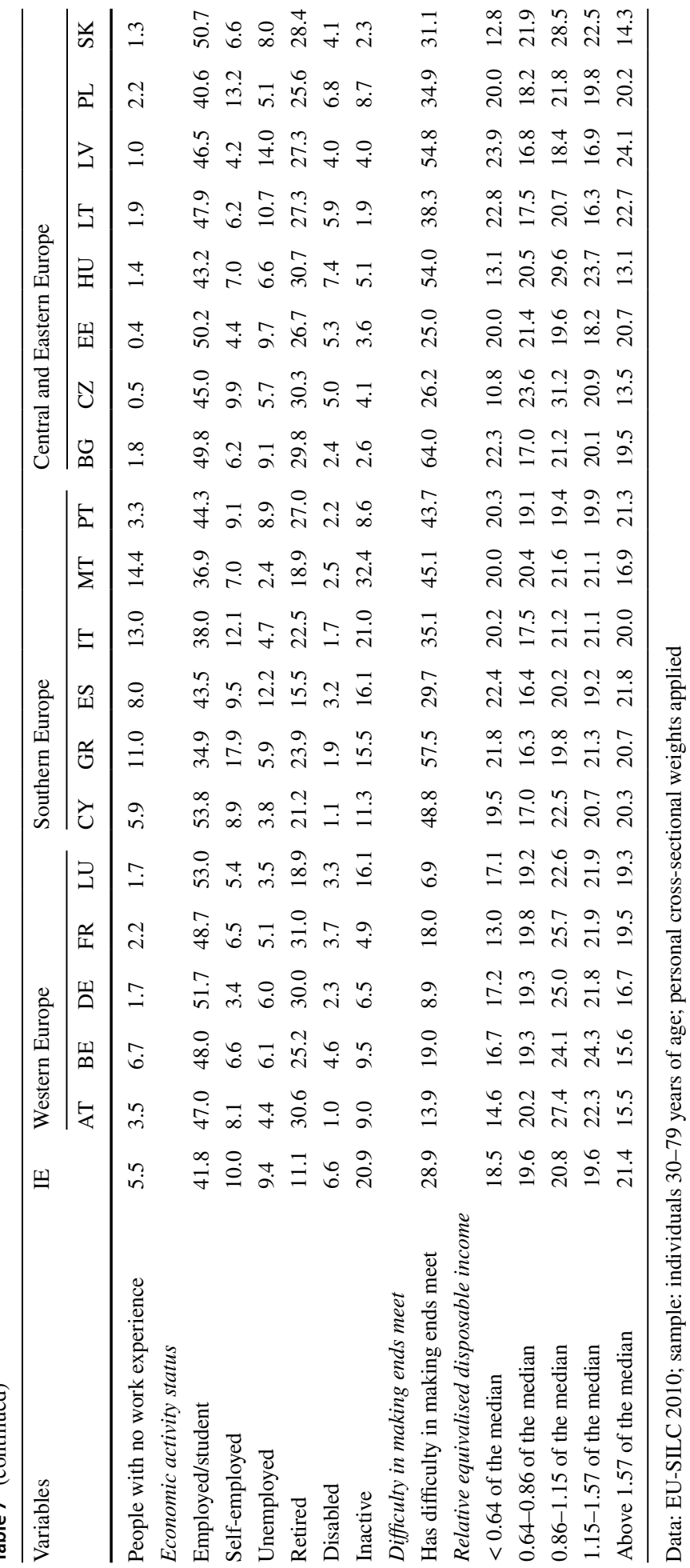




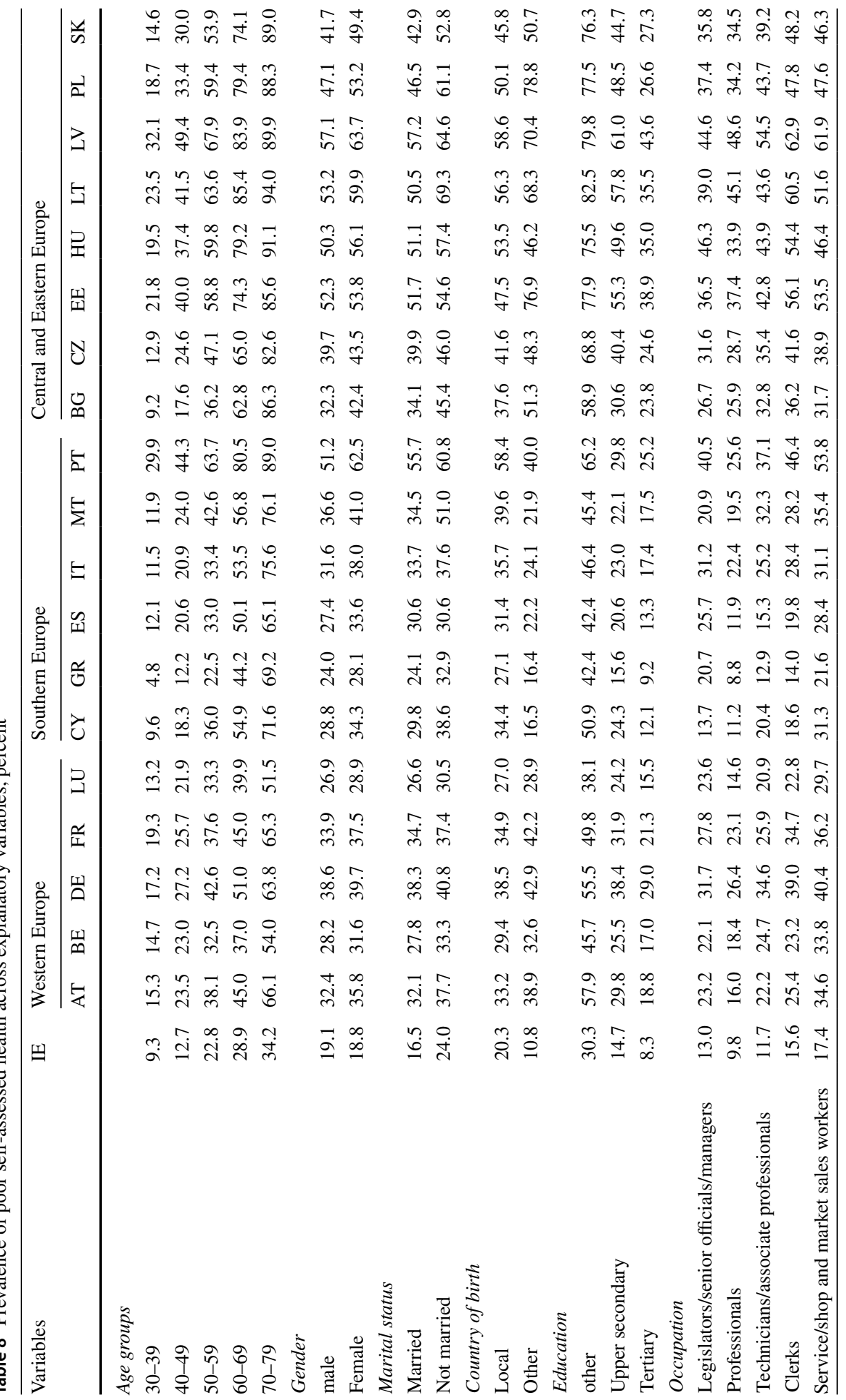




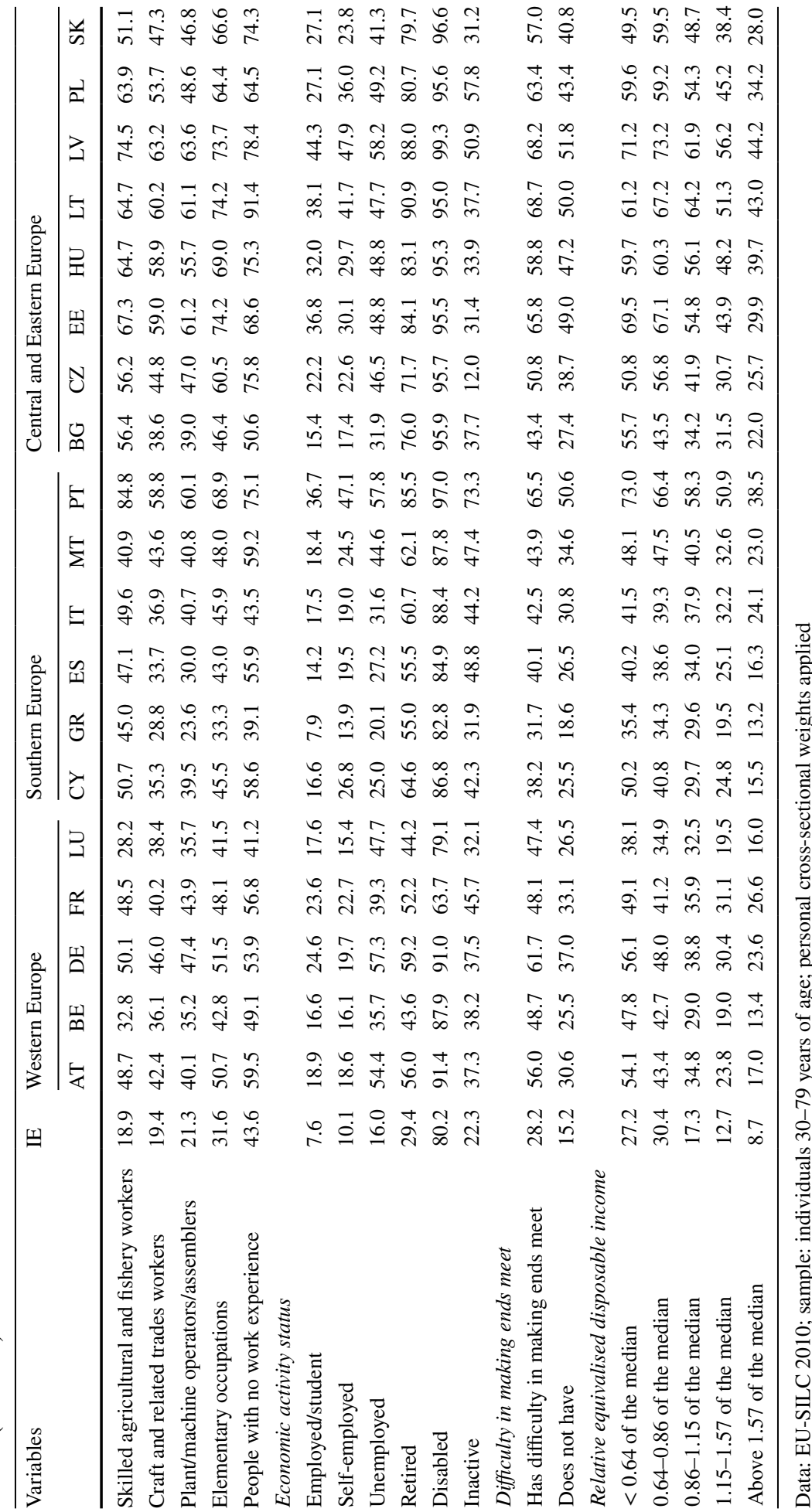




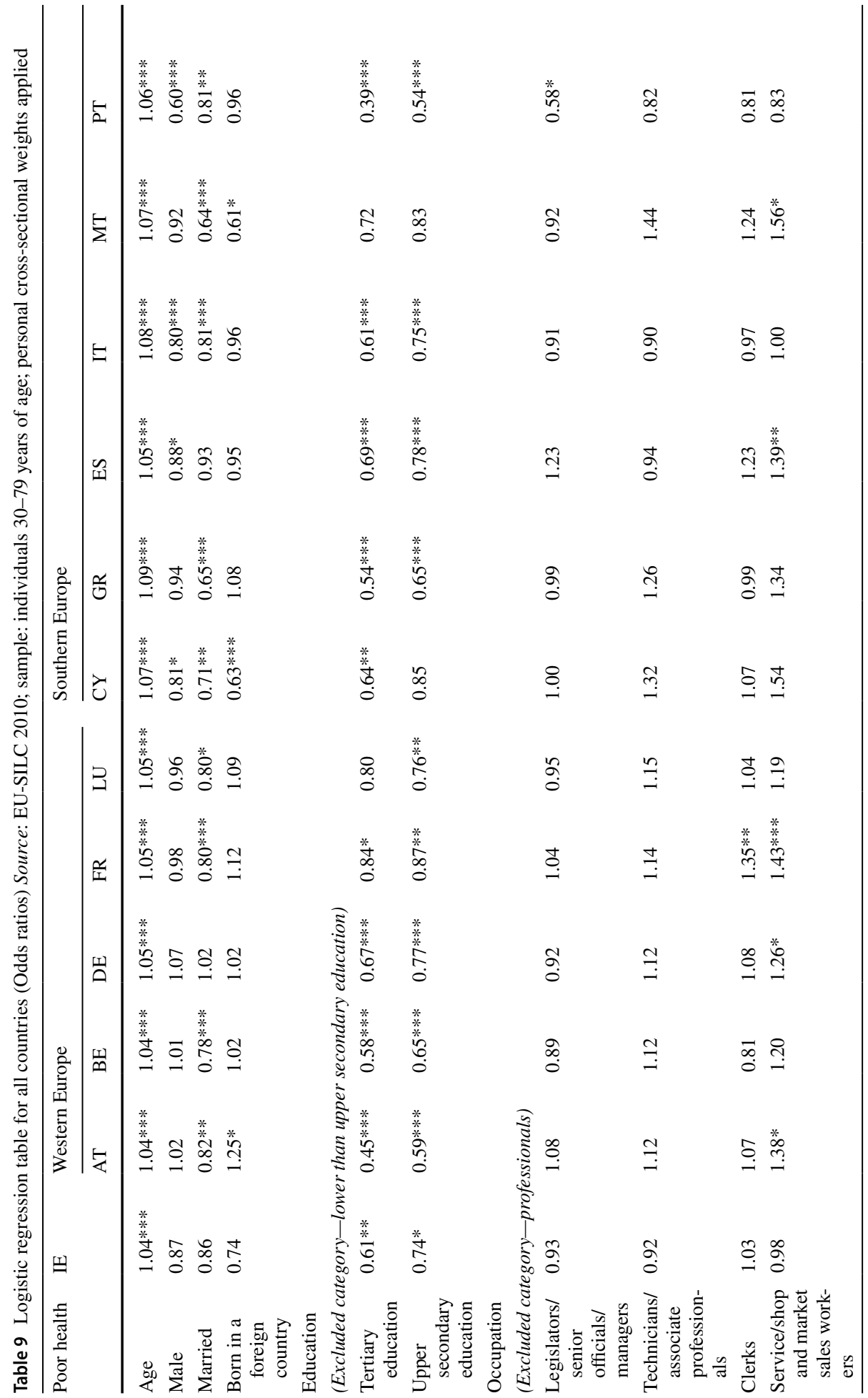




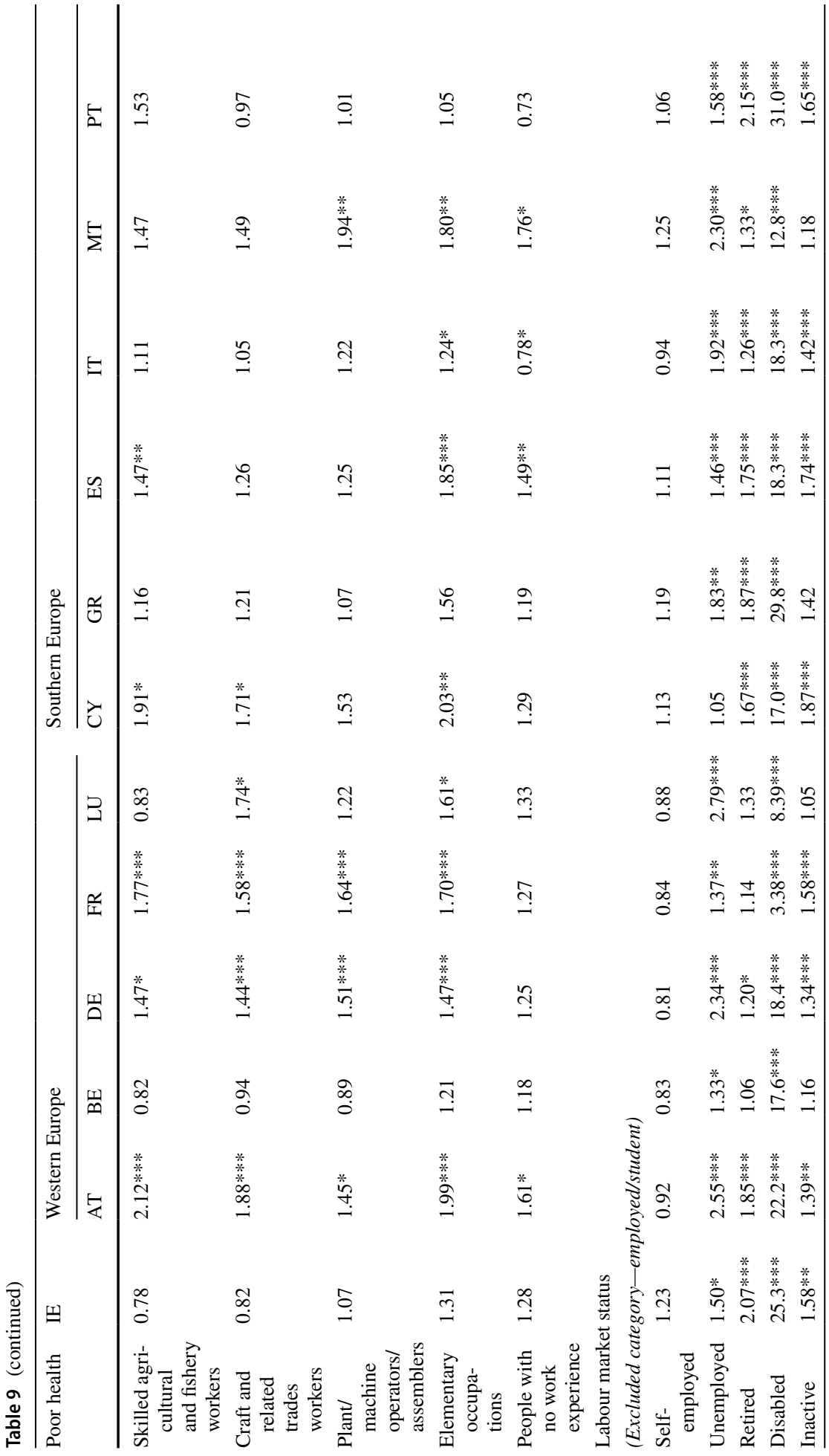




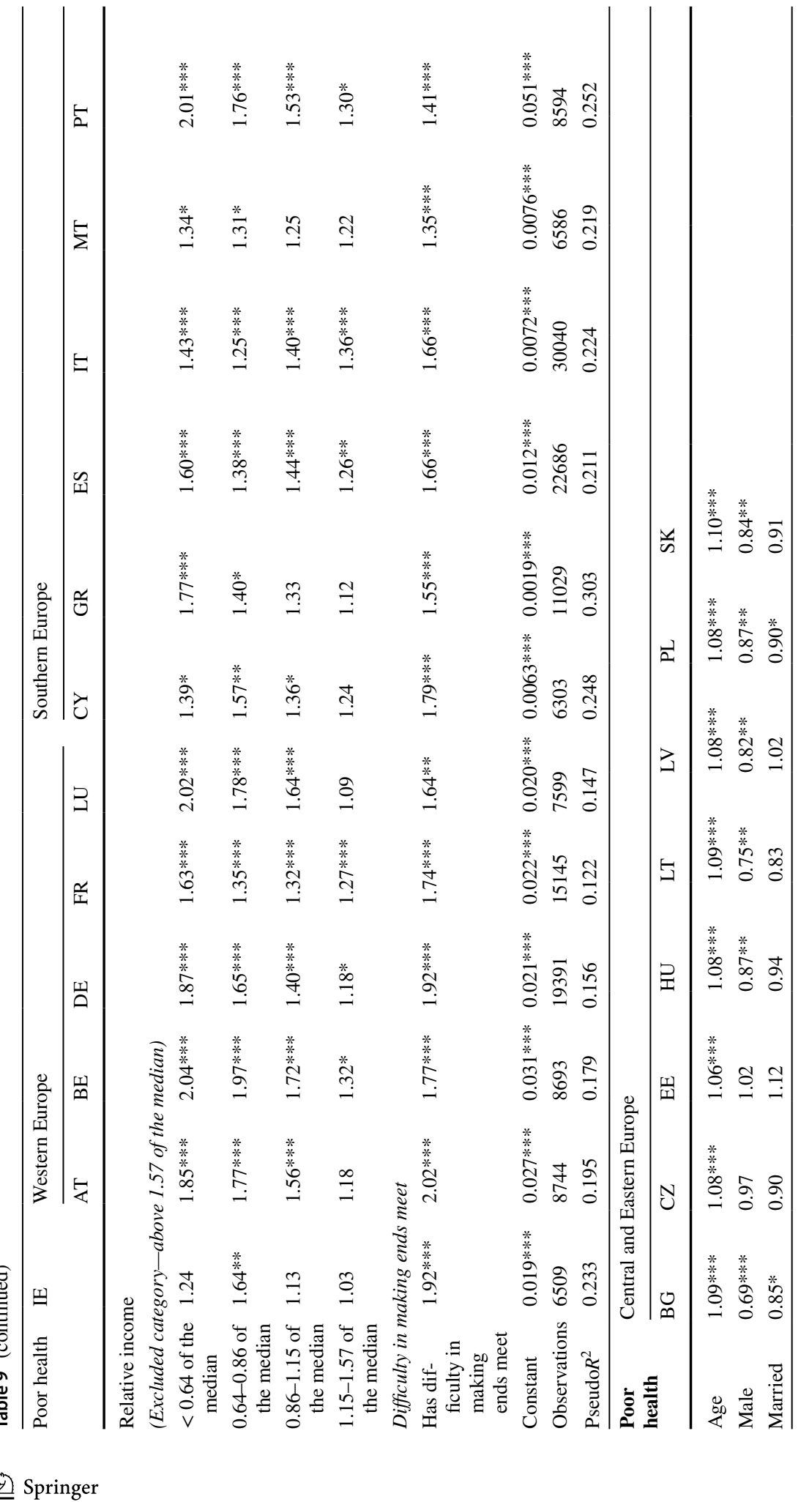




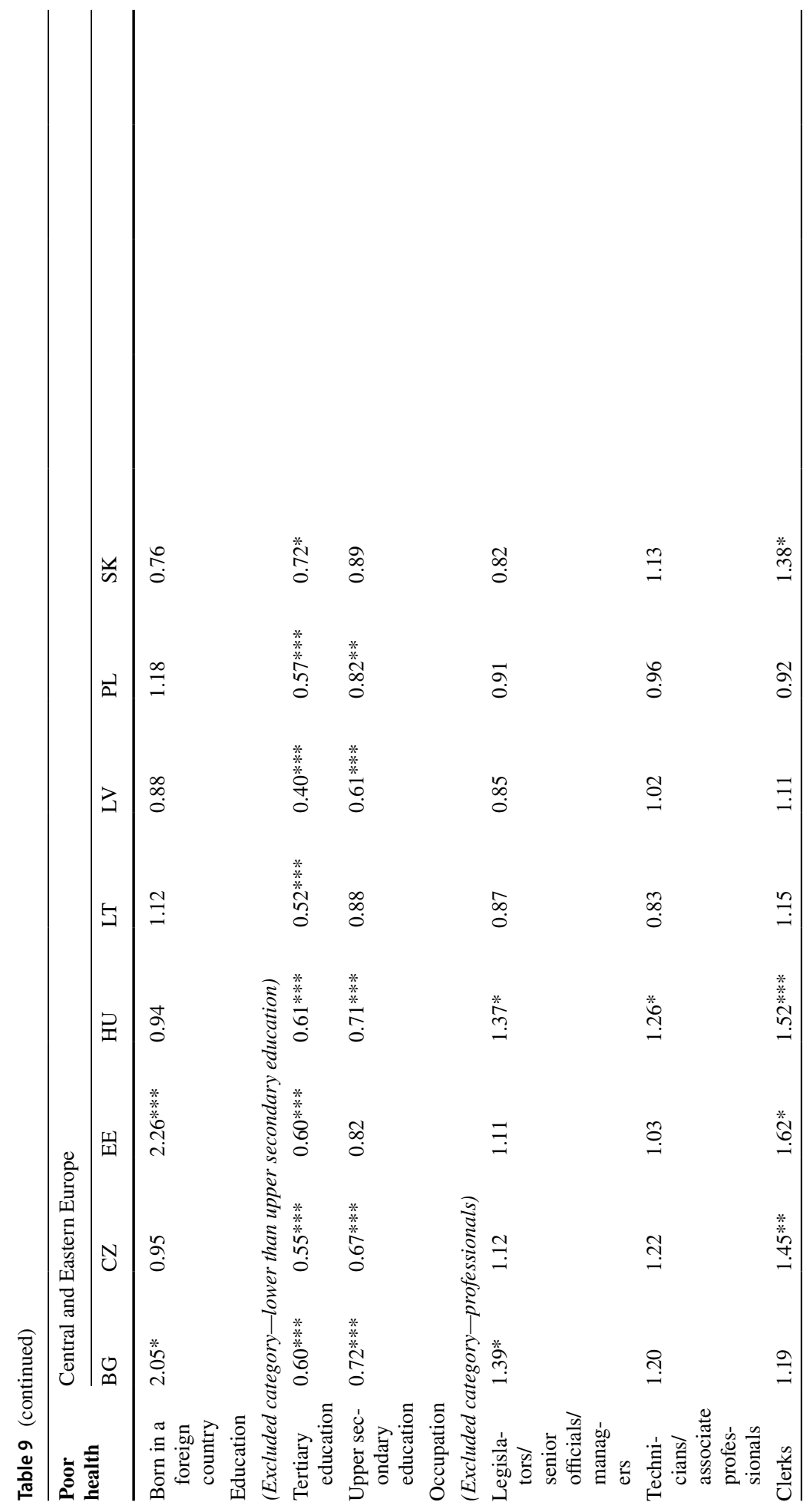




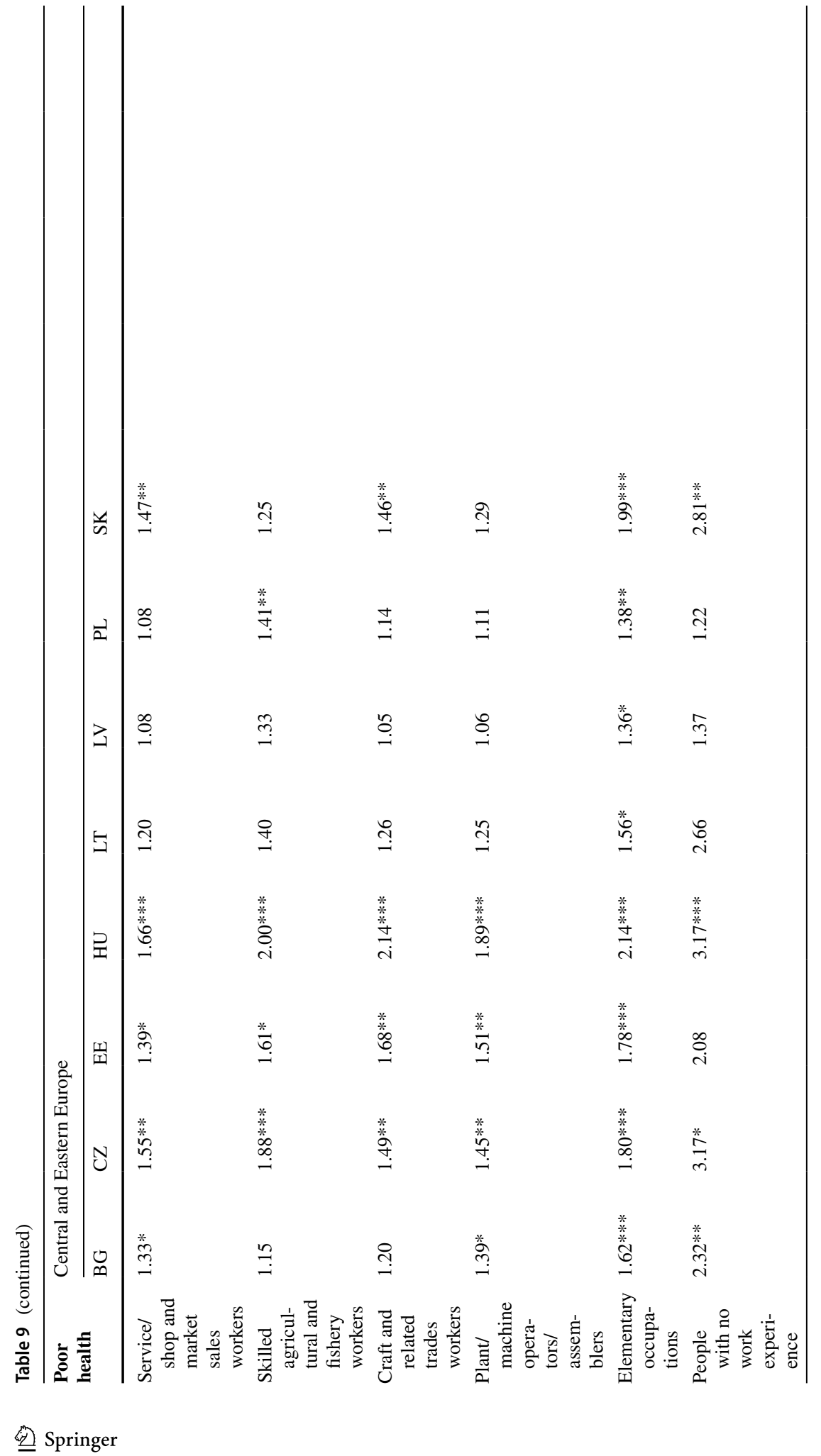




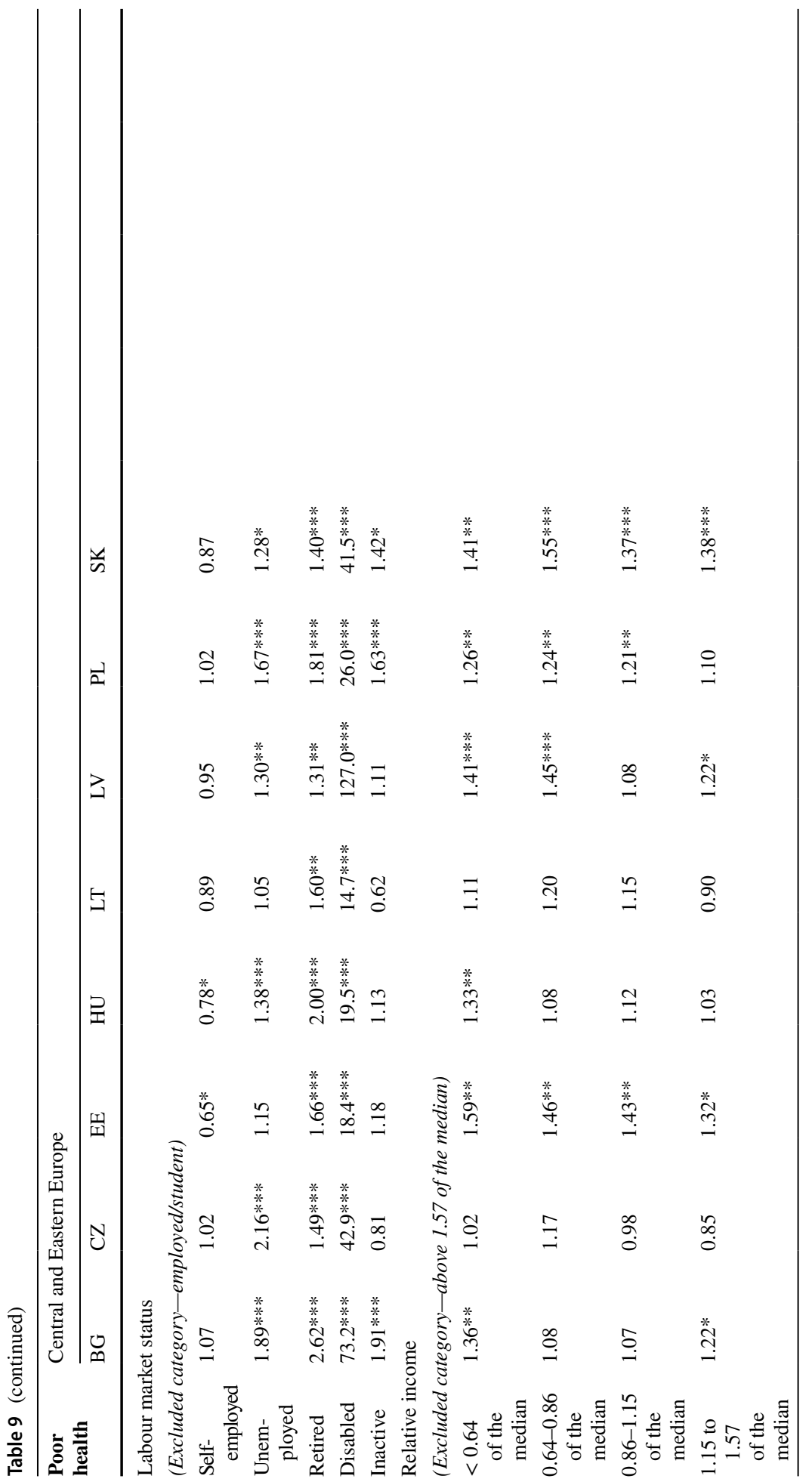




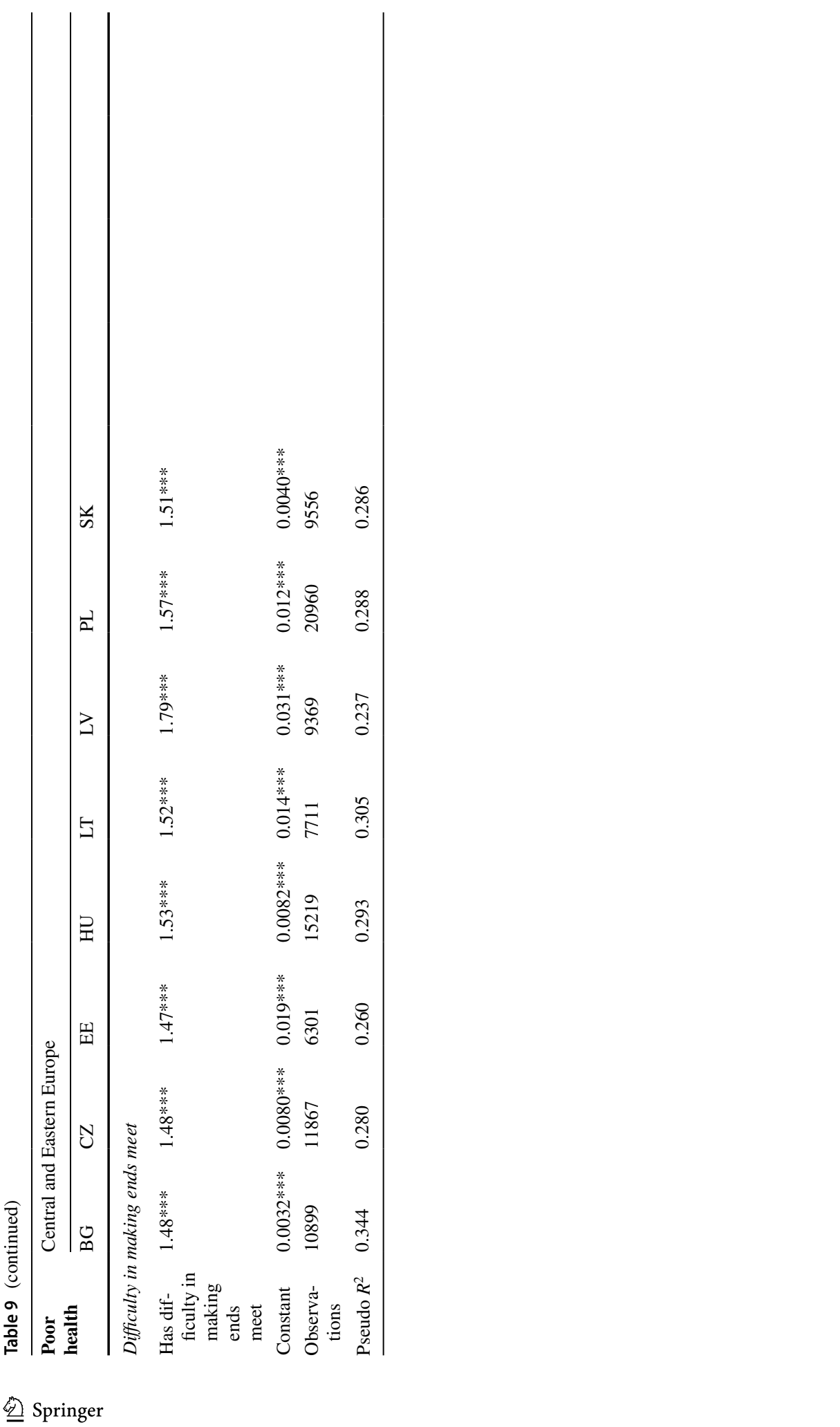



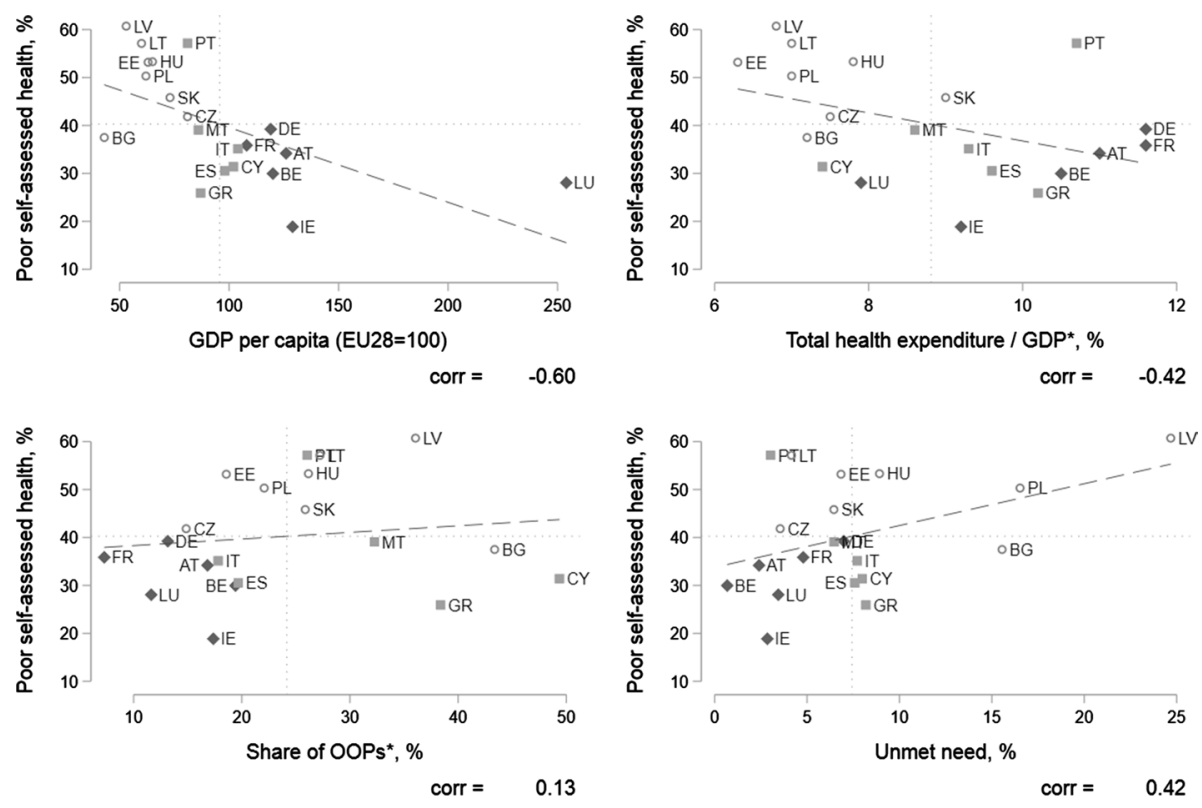

Western Europe - Southern Europe

- Central and Eastern Europe

- Linear fit

Fig. 6 Self-assessed health versus economic and healthcare indicators Sources: EU-SILC 2010 (adults age 30-79), *OECD (2012) (2010 or nearest year)

\section{References}

Adler, N. E., \& Newman, K. (2002). Socioeconomic disparities in health: Pathways and policies. Health Affairs, 21(2), 60-76.

Adler, N. E., \& Ostrove, J. M. (2006). Socioeconomic status and health: What we know and what we don't. Annals of the New York Academy of Sciences, 896(1), 3-15.

Altonji, J. G., Bharadwaj, P., \& Lange, F. (2012). Changes in the characteristics of American youth: Implications for adult outcomes. Journal of Labor Economics, 30(4), 783-828.

Arber, S., Fenn, K., \& Meadows, R. (2014). Subjective financial well-being, income and health inequalities in mid and later life in Britain. Social Science and Medicine, 100, 12-20.

Bago d'Uva, T., O'Donnell, O., \& van Doorslaer, E. (2008). Differential health reporting by education level and its impact on the measurement of health inequalities among older Europeans. International Journal of Epidemiology, 37(6), 1375-1383.

Bargain, O. (2012). Decomposition analysis of distributive policies using behavioural simulations. International Tax and Public Finance, 19(5), 708-731.

Bartley, M. (1994). Unemployment and ill health: Understanding the relationship. Journal of Epidemiology and Community Health, 48(4), 333-337.

Bartley, M., \& Plewis, I. (2002). Accumulated labour market disadvantage and limiting long-term illness: Data from the 1971-1991 Office for National Statistics' Longitudinal Study. International Journal of Epidemiology, 31(2), 336-341.

Bartley, M., Blane, D., \& Montgomery, S. (1997). Socioeconomic determinants of health: Health and the life course: Why safety nets matter. British Medical Journal, 314(7088), 1194-1196.

Bartley, M., Sacker, A., \& Clarke, P. M. (2004). Employment status, employment conditions, and limiting illness: Prospective evidence from the British household panel survey 1991-2001. Journal of Epidemiology and Community Health, 58(6), 501-506. 
Baum, A., Garofalo, J. P., \& Yali, A. M. (1999). Socioeconomic status and chronic stress: Does stress account for ses effects on health? Annals of the New York Academy of Sciences, 896(1), 131-144.

Benzeval, M., \& Judge, K. (2001). Income and health: The time dimension. Social Science and Medicine, 52(9), 1371-1390.

Benzeval, M., Taylor, J., \& Judge, K. (2000). Evidence on the relationship between low income and poor health: Is the government doing enough? Fiscal Studies, 21(3), 375-399.

Bergqvist, K., Yngwe, M. A., \& Lundberg, O. (2013). Understanding the role of welfare state characteristics for health and inequalities-An analytical review. BMC Public Health, 13(1), 1234.

Biewen, M. (2012). Additive decompositions with interaction effects No. 6730. Discussion Paper series, Forschungsinstitut zur Zukunft der Arbeit.

Black, D. (1982). Inequalities in health: The Black report. New York: Penguin Books.

Blinder, A. S. (1973). Wage discrimination: Reduced form and structural estimates. The Journal of Human Resources, 8(4), 436-455.

Bond, J., Dickinson, H. O., Matthews, F., Jagger, C., \& Brayne, C. (2006). Self-rated health status as a predictor of death, functional and cognitive impairment: A longitudinal cohort study. European Journal of Ageing, 3(4), 193-206.

Bourguignon, F., Ferreira, F. H. G., \& Leite, P. G. (2007). Beyond Oaxaca-Blinder: Accounting for differences in household income distributions. The Journal of Economic Inequality, 6(2), 117-148.

Braveman, P., Cubbin, C., Egerter, S., Williams, D. R., \& Pamuk, E. (2010). Socioeconomic disparities in health in the United States: What the patterns tell us. American Journal of Public Health, 100(Suppl), S186-96.

Brennenstuhl, S., Quesnel-Vallée, A., \& McDonough, P. (2012). Welfare regimes, population health and health inequalities: A research synthesis. Journal of Epidemiology and Community Health, 66(5), $397-409$.

Carlson, P. (2004). The European health divide: A matter of financial or social capital? Social Science and Medicine, 59(9), 1985-1992.

Cavelaars, A. E. J. M., Kunst, A. E., Geurts, J. J. M., Crialesi, R., Grötvedt, L., Helmert, U., et al. (1998). Differences in self reported morbidity by educational level: A comparison of 11 Western European countries. Journal of Epidemiology and Community Health (1979), 52(4), 219-227.

Charasse-Pouélé, C., \& Fournier, M. (2006). Health disparities between racial groups in South Africa: A decomposition analysis. Social Science and Medicine (1982), 62(11), 2897-914.

Costa-Font, J., \& Hernandez-Quevedo, C. (2013). Inequalities in self-reported health: A meta-regression analysis (No. 13/05). HEDG, c/o Department of Economics, University of York.

Crossley, T. F., \& Kennedy, S. (2002). The reliability of self-assessed health status. Journal of Health Economics, 21(4), 643-658.

CSDH (2008). Closing the gap in a generation: Health equity through action on the social determinants of health: Final Report of the Commission on Social Determinants of Health. World Health Organization.

Cutler, D. M., \& Lleras-Muney, A. (2006). Education and health: Evaluating theories and evidence. Cambridge: National Bureau of Economic Research.

DiNardo, J., Fortin, N., \& Lemieux, T. (1996). Labor market institutions and the distribution of wages 1973-1992-A semiparametric approach. Econometrica.

Duncan, G. J., Daly, M. C., McDonough, P., \& Williams, D. R. (2002). Optimal indicators of socioeconomic status for health research. American Journal of Public Health, 92(7), 1151-1157.

Ecob, R., \& Davey Smith, G. (1999). Income and health: What is the nature of the relationship? Social Science and Medicine, 48(5), 693-705.

Eikemo, T., Bambra, C., Joyce, K., \& Dahl, E. (2008a). Welfare state regimes and income-related health inequalities: A comparison of 23 European countries. European Journal of Public Health, 18(6), 593-9.

Eikemo, T., Huisman, M., Bambra, C., \& Kunst, A. E. (2008b). Health inequalities according to educational level in different welfare regimes: A comparison of 23 European countries. Sociology of Health and Illness, 30(4), 565-582.

Eikemo, T. A., Bambra, C., Judge, K., \& Ringdal, K. (2008c). Welfare state regimes and differences in selfperceived health in Europe: A multilevel analysis. Social Science and Medicine, 66(11), 2281-2295.

Espelt, A., Borrell, C., Rodríguez-Sanz, M., Muntaner, C., Pasarín, M. I., Benach, J., et al. (2008). Inequalities in health by social class dimensions in European countries of different political traditions. International Journal of Epidemiology, 37(5), 1095-1105.

Esping-Andersen, G. (1990). The three worlds of welfare capitalism. Princeton: Princeton University Press.

Ettner, S. L. (1996). New evidence on the relationship between income and health. Journal of Health Economics, 15(1), 67-85. 
EUROSTAT (2010a). Life expectancy by age and sex. Statistics Database. https://ec.europa.eu/eurostat/ data/database

EUROSTAT (2010b). Population by educational attainment level, sex and age. Statistics Database. https:// ec.europa.eu/eurostat/data/database

Ferrarini, T., Nelson, K., \& Sjöberg, O. (2014). Unemployment insurance and deteriorating self-rated health in 23 European countries. Journal of Epidemiology and Community Health, 68(7), 657-662.

Fortin, N., Lemieux, T., \& Firpo, S. (2010). Decomposition methods in economics. Handbook of Labor Economics, 4, 1-102.

Frijters, P., Haisken-DeNew, J. P., \& Shields, M. A. (2005). The causal effect of income on health: Evidence from German reunification. Journal of Health Economics, 24(5), 997-1017.

Galea, S., Riddle, M., Kaplan, G., \& a., (2010). Causal thinking and complex system approaches in epidemiology. International Journal of Epidemiology, 39(1), 97-106.

Galobardes, B., Shaw, M., Lawlor, D. A., \& Lynch, J. W. (2006). Indicators of socioeconomic position (part 2). Journal of Epidemiology and Community Health, 60(2), 95.

Gelbach, J. B. (2009). When do covariates matter, 7-9.

Giavazzi, F., Schiantarelli, F., \& Serafinelli, M. (2009). Culture, policies and labor market outcomes. Technical report.

Goldman, N. (2001). Social inequalities in health. Annals of the New York Academy of Sciences, 954(1), 118-139.

Graham, H. (2004). Social determinants and their unequal distribution: Clarifying policy understandings. The Milbank Quarterly, 82(1), 101-24.

Hacker, B. (2009). Hybridization instead of clustering: Transformation processes of welfare policies in Central and Eastern Europe. Social Policy and Administration, 43(2), 152.

Hildebrand, V., \& Van Kerm, P. (2009). Income inequality and self-rated health status: Evidence from the European Community Household Panel. Demography, 46(4), 805-825.

Idler, E. L., \& Benyamini, Y. (1997). Self-rated health and mortality: A review of twenty-seven community studies. Journal of Health and Social Behavior, 38(1), 21-37.

Johar, M., Jones, G., Keane, M. P., Savage, E., \& Stavrunova, O. (2013). Discrimination in a universal health system: Explaining socioeconomic waiting time gaps. Journal of Health Economics, 32(1), 181-94.

Johnston, D. W., \& Lee, W.-S. (2011). Explaining the female black-white obesity gap: A decomposition analysis of proximal causes. Demography, 48(4), 1429-1450.

Jürges, H. (2009). Health inequalities by education, income and wealth: A comparison of 11 European countries and the US. Applied Economics Letters, 17(1), 87-91.

Jylhä, M., Guralnik, J. M., Ferrucci, L., Jokela, J., \& Heikkinen, E. (1998). Is self-rated health comparable across cultures and genders? The Journals of Gerontology Series B: Psychological Sciences and Social Sciences, 53(3), S144-S152.

Katchadourian, V., \& Cambois, E. (2013). Analysis of 2009 EU-SILC national survey samples. EHLEIS: Technical report.

Korpi, T. (2001). Accumulating disadvantage. Longitudinal analyses of unemployment and physical health in representative samples of the Swedish population. European Sociological Review, 17(3), 255-273.

Kunst, A. E., Groenhof, F., Andersen, O., Borgan, J. K., Costa, G., Desplanques, G., et al. (1999). Occupational class and ischemic heart disease mortality in the United States and 11 European countries. American Journal of Public Health, 89(1), 47-53.

Kunst, A. E., Bos, V., Lahelma, E., Bartley, M., Lissau, I., Regidor, E., et al. (2005). Trends in socioeconomic inequalities in self-assessed health in 10 European countries. International Journal of Epidemiology, 34(2), 295-305.

Lahelma, E., Martikainen, P., Laaksonen, M., \& Aittomäki, A. (2004). Pathways between socioeconomic determinants of health. Journal of Epidemiology and Community Health, 58(4), 327-332.

Lahelma, E., Martikainen, P., Rahkonen, O., Roos, E., \& Saastamoinen, P. (2005). Occupational class inequalities across key domains of health: Results from the Helsinki Health Study. The European Journal of Public Health, 15(5), 504-510.

Lindeboom, M., \& van Doorslaer, E. (2004). Cut-point shift and index shift in self-reported health. Journal of Health Economics, 23(6), 1083-1099.

Lundberg, O., \& Manderbacka, K. (1996). Assessing reliability of a measure of self-rated health. Scandinavian Journal of Public Health, 24(3), 218-224.

Lynch, J., \& Kaplan, G. (2000). Socioeconomic position. Social Epidemiology, 1, 13-35.

Mackenbach, J. P. (2006). Health inequalities: Europe in profile. Number February.

Mackenbach, J. P. (2012). The persistence of health inequalities in modern welfare states: The explanation of a paradox. Social Science and Medicine, 75(4), 761-769. 
Mackenbach, J. P. (2014). Cultural values and population health: A quantitative analysis of variations in cultural values, health behaviours and health outcomes among 42 European countries. Health and Place, 28, 116-132.

Mackenbach, J. P., \& Bakker, M. J. (2003). Tackling socioeconomic inequalities in health: Analysis of European experiences. The Lancet, 362(9393), 1409-1414.

Mackenbach, J. P., Martikainen, P., Looman, C. W. N., Dalstra, J. A. A., Kunst, A. E., \& Lahelma, E. (2005). The shape of the relationship between income and self-assessed health: An international study. International Journal of Epidemiology, 34(2), 286-293.

Mackenbach, J. P., Stirbu, I., Roskam, A.-J. R., Schaap, M., Menvielle, G., Leinsalu, M., et al. (2008). Socioeconomic inequalities in health in 22 European countries. New England Journal of Medicine, 358(23), 2468-2481.

Mackenbach, J. P., Meerding, W. J., \& Kunst, A. E. (2011). Economic costs of health inequalities in the European Union. Journal of Epidemiology and Community Health, 65(5), 412-419.

Mackenbach, J., McKee, M., Mackenbach, J. P., \& McKee, M. (2013). Comparative analysis of national health policies. In: Successes and failures in health policy in Europe: Four decades of divergent trends and converging challenges (pp. 255-283).

Mackenbach, J. P., Kulhánová, I., Bopp, M., Deboosere, P., Eikemo, T. A., Hoffmann, R., et al. (2015). Variations in the relation between education and cause-specific mortality in 19 European populations: A test of the "fundamental causes" theory of social inequalities in health. Social Science and Medicine, 127, 51-62.

Marmot, M. G. (2002). The influence of income on health: Views of an epidemiologist. Health Affairs, 21(2), 31-46.

Marmot, M. G., \& Shipley, M. J. (1996). Do socioeconomic differences in mortality persist after retirement? 25 year follow up of civil servants from the first Whitehall study. British Medical Journal, 313(7066), 1177-80.

McKee-Ryan, F., Song, Z., Wanberg, C. R., \& Kinicki, A. J. (2005). Psychological and physical well-being during unemployment: A meta-analytic study. Journal of Applied Psychology, 90(1), 53-76.

Muntaner, C., Borrell, C., Ng, E., Chung, H., Espelt, A., Rodriguez-Sanz, M., et al. (2011). Politics, welfare regimes, and population health: Controversies and evidence. Sociology of Health and Illness, 33(6), 946-964.

Nolan, A., Barry, S., Burke, S., \& Thomas, S. (2015). The impact of the crisis on the health system and health in Ireland. Economic Crisis, Health Systems and Health in Europe, 143.

Nolte, E., \& McKee, M. (2004). Changing health inequalities in east and west Germany since unification. Social Science and Medicine, 58(1), 119-136.

Nusselder, W. J., Looman, C. W. N., Van Oyen, H., Robine, J. M., \& Jagger, C. (2010). Gender differences in health of EU10 and EU15 populations: The double burden of EU10 men. European Journal of Ageing, 7(4), 219-227.

Oaxaca, R. (1973). Male-Female wage differentials in urban labor markets. International Economic Review, 14(3), 693-709.

OECD (2012a). Education at a glance 2012: OECD indicators.

OECD (2012b). Health at a glance: Europe 2012.

Olsen, K. M., \& Dahl, S.-A. (2007). Health differences between European countries. Social Science and Medicine, 64(8), 1665-1678.

Paul, K. I., \& Moser, K. (2009). Unemployment impairs mental health: Meta-analyses. Journal of Vocational Behavior, 74(3), 264-282.

Popham, F., Dibben, C., \& Bambra, C. (2013). Are health inequalities really not the smallest in the Nordic welfare states? A comparison of mortality inequality in 37 countries. Journal of Epidemiology and Community Health, 67(5), 412-8.

Preston, S. H. (1975). The changing relation between mortality and level of economic development. Population Studies, 29(2), 231-248.

Price, R. H., Choi, J. N., \& Vinokur, A. D. (2002). Links in the chain of adversity following job loss: How financial strain and loss of personal control lead to depression, impaired functioning, and poor health. Journal of Occupational Health Psychology, 7(4), 302-312.

Quaglio, G., Karapiperis, T., Van Woensel, L., Arnold, E., \& McDaid, D. (2013). Austerity and health in Europe. Health Policy, 113(1), 13-19.

Ross, C. E., \& Mirowsky, J. (1995). Does employment affect health? Journal of Health and Social Behavior, 36(3), 230-43.

Sen, A. (2002). Health: Perception versus observation: Self reported morbidity has severe limitations and can be extremely misleading. BMJ, 324, 860-861.

Shavers, V. L. (2007). Measurement of socioeconomic status in health disparities research. Journal of the National Medical Association, 99(9), 1013. 
Shorrocks, A. F. (2013). Decomposition procedures for distributional analysis: A unified framework based on the Shapley value. The Journal of Economic Inequality, 11(1), 99-126.

Siegel, M., Vogt, V., \& Sundmacher, L. (2014). From a conservative to a liberal welfare state: Decomposing changes in income-related health inequalities in Germany, 1994-2011. Social Science and Medicine, 1982(108), 10-9.

Smith, G. D., Neaton, J. D., Wentworth, D., Stamler, R., \& Stamler, J. (1998). Mortality differences between black and white men in the USA: Contribution of income and other risk factors among men screened for the MRFIT. The Lancet, 351(9107), 934-939.

Smith, G. D., Chaturvedi, N., Harding, S., Nazroo, J., Williams, R., \& Smith, D. (2003). Ethnic inequalities in health: A review of UK epidemiological evidence. Health inequalities. Lifecourse Approaches, 10, 271-310.

Solar, O. \& Irwin, A. (2010). A conceptual framework for action on the social determinants of health. Social Determinants of Health Discussion Paper 2 (Policy and Practice).

Sologon, D. M., Van Kerm, P., Li, J., \& O’Donoghue, C. (2017). Demography, market returns, policy and behavioural response: Understanding cross-national differences in income inequality. LISER working paper series (Forthcoming).

Van de Poel, E., \& O'donnell, O., and Van Doorslaer, E., (2009). What explains the rural-urban gap in infant mortality: Household or community characteristics? Demography, 46(4), 827-850.

van Doorslaer, E., \& Koolman, X. (2004). Explaining the differences in income-related health inequalities across European countries. Health Economics, 13(7), 609-628.

van Doorslaer, E., Wagstaff, A., Bleichrodt, H., Calonge, S., Gerdtham, U.-G., Gerfin, M., et al. (1997). Income-related inequalities in health: Some international comparisons. Journal of Health Economics, 16(1), 93-112.

Verbrugge, L. M. (1979). Marital status and health. Journal of Marriage and Family, 41(2), 267-285.

von dem Knesebeck, O., Verde, P. E., \& Dragano, N. (2006). Education and health in 22 European countries. Social Science and Medicine, 63(5), 1344-1351.

Waldron, I. (1996). Marriage protection and marriage selection: Prospective evidence for reciprocal effects of marital status and health. Social Science and Medicine. Part F: Medical and Social Ethics, 43(1), 113.

Whitehead, M. (1992). The concepts and principles of equity and health. International Journal of Health Services, 22(3), 429-445.

Whitehead, M., Dahlgren, G., \& Gilson, L. (2001a). Developing the policy response to inequities in health: A global perspective. In Challenging inequities in health: From ethics to action (pp. 309-323).

Whitehead, M., Dahlgren, G., \& Gilson, L. (2001b). Developing the policy response to inequities in Health: A global perspective. In T. Evans, M. Whitehead, A. Bhuiya, F. Diderichsen, \& M. Wirth (Eds.), Challenging inequities in health care: From ethics to action (pp. 309-322). New York: Oxford University Press.

WHO (2012). Health 2020: A European policy framework supporting action across government and society for health and well-being. In Proceedings of regional committee for Europe.

WHO. (2013). Handbook on health inequality monitoring with a special focus on low-and middle-income countries. New York: WHO.

Wilkinson, R. G. (1992). Income distribution and life expectancy. British Medical Journal, 304(6820), 165.

World Bank (1993). World Development Report 1993. The World Bank.

Yamada, C., Moriyama, K., \& Takahashi, E. (2012). Self-rated health as a comprehensive indicator of lifestyle-related health status. Environmental Health and Preventive Medicine, 17(6), 457-462.

Zatonski, W. A., \& Bhala, N. (2012). Changing trends of diseases in Eastern Europe: Closing the gap. Public Health, 126(3), 248-252.

Publisher's Note Springer Nature remains neutral with regard to jurisdictional claims in published maps and institutional affiliations. 